Portland State University

PDXScholar

\title{
When You Aren't Who Your Friends Are: the Moderating Influence of Racial Similarity on the Association Between Friendships and Mental Well- Being
}

Philip Tostado

Portland State University

Follow this and additional works at: https://pdxscholar.library.pdx.edu/open_access_etds

Part of the Social Psychology Commons, and the Sociology Commons Let us know how access to this document benefits you.

\section{Recommended Citation}

Tostado, Philip, "When You Aren't Who Your Friends Are: the Moderating Influence of Racial Similarity on the Association Between Friendships and Mental Well-Being" (2017). Dissertations and Theses. Paper 4018.

https://doi.org/10.15760/etd.5902

This Thesis is brought to you for free and open access. It has been accepted for inclusion in Dissertations and Theses by an authorized administrator of PDXScholar. Please contact us if we can make this document more accessible: pdxscholar@pdx.edu. 
When You Aren't Who Your Friends Are:

The Moderating Influence of Racial Similarity on the Association between Friendships and Mental Well-Being

by

Philip Tostado

A thesis submitted in fulfillment of the requirements for the degree of

\author{
Master of Arts \\ in \\ Sociology
}

Thesis Committee:

Melissa Thompson, Chair

José Padín

Lindsey Wilkinson

Portland State University

2017 
(C)2017 Philip Tostado 


\begin{abstract}
Friendships are a mental health resource for adolescents. Their availability and strength have been shown to predict lower levels of depression, higher self esteem, and higher life satisfaction. They can also alleviate the stress that often leads to negative mental health outcomes. However, studies examining the stress process rarely consider the fact that social networks like friendship groups are not a static resource that effects all people the same way. Rather, demographic characteristics of both the individual and their friends could change the role of friendship networks within the stress process.

In this thesis, I investigate the importance of one such demographic characteristic: race. Racial and ethnic diversity continues to grow in the United States, contributing to an increase interracial and interethnic friendships. It is important to understand what impact racial difference might have on the stress process. In addition to using Leonard Peralin's stress process model to understand these potential effects, I draw upon Gordon Allport's Contact theory to inform my analysis. Contact Theory attempts to explain why and how intergroup contact leads to changes in racial attitudes. Increases in positive racial attitudes may lower unique stressors often experienced my racial minorities such as racial prejudice and acculturation. This research project provides a starting point for deeper analyses examining how contact theory and the stress process function together. I ask if racially diverse friendship networks affect adolescent mental well being (as measured by mental health and self-esteem) and if the race of the respondent moderate the effects of racial diversity in friendship networks on mental well-being.
\end{abstract}


To answer these questions, I perform secondary data analysis of survey responses from The National Longitudinal Study of Adolescent to Adult Health. I use public-use, cross-sectional data of adolescents from Wave 1 ('94-'95). Linear regression models predicting adolescent mental health found that racial difference in friendship networks is negatively associated with mental health for white adolescents. For Asian respondents, linear regression models found that racial difference in friendship networks was positively associated with both mental health and self-esteem. Results on Hispanic, Black, and "Other" race adolescents were non-significant.

These results suggest that racial difference in friendship networks have varying associations on mental well-being that depend on the race of the adolescent. White adolescents with more diverse friend groups may experience increased stress resulting from an increased awareness of the racial prejudice that affects their friend's lives. Asian adolescents may benefit from more diverse friend groups because it allows them to find a "sense of belonging" in environments where there is less opportunity to have same-race friendship networks. They also might face less discrimination from different-race peers, allowing the social support benefits of a racially different friendship networks to outweigh any increases in perceived discrimination from peers. The results indicate that future studies should continue studying how demographic characteristics influence the stress process, including the role of social networks. Policies should aim to provide educational resources teaching adolescents how to handle experiences of prejudice and to create positive points of contact for different race peers. Future studies should assess the validity of these results by performing longitudinal analyses that can provide information 
on how racially different friendship networks buffer specific stressors and discover if the relationships found in this analysis change over time. 
Dedicated to my grandmothers,

Sandra Cruciotti and Mary Tostado.

Thank you for believing in me. 


\section{Acknowledgments}

Special thanks to all those who have assisted me on this thesis. Melissa Thompson, José Padín, and Lindsey Wilkinson have been a great committee of scholars who have not only provided expertise when needed but also pushed me to succeed on this research project. I would also like to thank the Portland State University department as a whole. You contribute to an academic environment the rewards discovery and exploration of newfound interests. I have enjoyed my time here because of all your efforts.

My cohort has also been essential to my success. Kyla Tompkins, Alexis DeVigal, Erin Savoia, and Rina James have been a critical social network resource that has kept me sane these last two years. Your ability to mediate increased stress have helped me maintain strong mental well-being and life satisfaction. I can't keep count of the amount of times you have all kept me accountable or were just there for me when I needed a break.

I would also like to thank all my family and friends for encouraging me to pursue graduate school and continue my education. Even though many of you live far away, you continue to reach out to me to see how I am doing. Your encouragement and interest in my success motivates me to keep growing. I especially cannot imagine how I would feel if I didn't have the support of my parents. Whenever I was feeling drained, I knew I could rely on my parents to send me a gift card to various restaurants or to let me rant on the phone about social science for an hour. 


\section{Table of Contents}

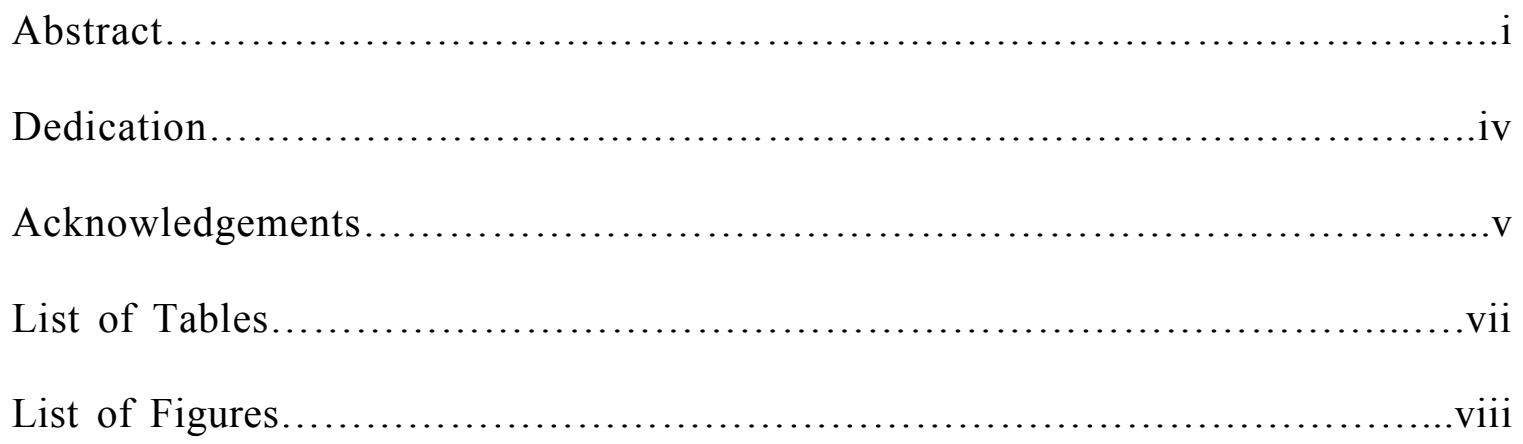

\section{Chapter 1}

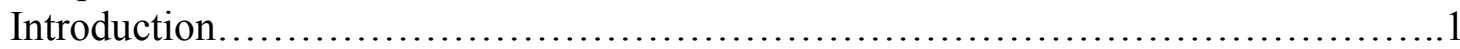

Chapter 2

Literature Review..........................................................4

Chapter 3

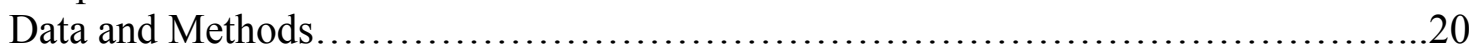

Chapter 4

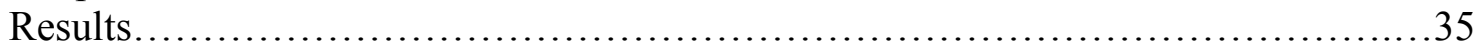

Chapter 5

Discussion and Conclusion.................................................... 55

References............................................................... 88

Appendices

A. Measures...................................................92

B. Supplemental Information.........................................97 


\section{List of Tables}

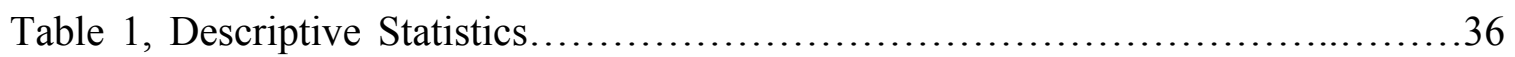

Table 2, T-Tests of Key Variables and Demographic Characteristics....................36

Table 3, Linear Unstandardized Coefficients from Linear Regression Models Predicting Adolescent Mental Health.........................................................

Table 4, Linear Unstandardized Coefficients from Linear Regression Models Predicting Asian Adolescent Mental Health................................................45

Table 5, Linear Unstandardized Coefficients from Linear Regression Models Predicting White Adolescent Mental Health..................................................46

Table 6, Linear Unstandardized Coefficients from Linear Regression Models Predicting Adolescent Self-Esteem........................................................49

Table 7, Linear Unstandardized Coefficients from Linear Regression Models Predicting Asian Adolescent Self-Esteem.................................................52

Table 8, Linear Unstandardized Coefficients from Linear Regression Models Predicting

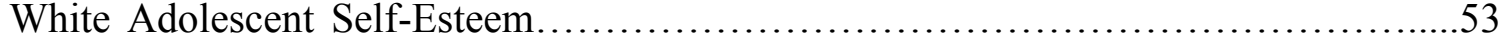




\section{List of Figures}

Figure 1, Concept Map of Hypothesized Relationships between Variables...............31

Figure 2, Race Comparisons on the Association between Mental Health Scores and Racial Difference in Adolescent Friendship Networks.............................42

Figure 3, Race Comparisons on the Association between Self-Esteem Scores and Racial Difference in Adolescent Friendship Networks...................................51

Figure 4, Sythesized Model of the Stress Process and Contact Theory..................65 


\section{Chapter 1: Introduction}

Friendships often provide the support necessary to overcome times of hardship. In adolescence especially, bonds with peers assist in the formation of an individual's identity (Ericson 1950). Peer rejection can lead to isolation, as an adolescent is unable to identify where they belong. Peer bonds are of primary importance in the development of an individual (Ericson 1950). Social support—including support from friends — is a key component of the stress process, a framework used to understand how stress leads to mental health outcomes (Pearlin 1989). Social support often provides a buffer that can negate or weaken the negative effects of psychological distress such as low mental wellbeing, depression, and anxiety (Pearlin 1989). Social status, including a person's race and gender, also plays a key role in the stress process. People with less social status within a society might face unique stressors like discrimination or acculturation, rely on different resources in order to cope with stress, and even experience different stress outcomes than other groups on the social ladder (Pearlin 1989; Turner 1999).

This study is motivated by a desire to explore whether or not the differences in social status of an adolescent's friendship network - an important form of social support — changes the effectiveness of social support on buffering or negating stress outcomes. Social support is not a static resource; rather, the people within one's social support network have certain characteristics that can influence their effectiveness in creating healthier outcomes for those they help. It is important to understand how different friendship characteristics might account for variation in health outcomes such as mental well-being. For example, a study on male-female best friendships found that 
people who have best friends of a different gender and sexual orientation report stronger mental health than those with only close friends of the same gender and sexual orientation (Baiocco et al 2014). This effect was especially pronounced for sexual minority youth, who might need "friendships of difference" to feel they have found acceptance and support among the "heterosexual majority" (Baiocco et al 2014). These findings lead me to ask if the variation in other demographic characteristics of friends such as race might lead to similar mental health outcomes for adolescents.

Research has not yet confirmed if such "friendships of difference" are similarly important for racial minorities. In fact, for some racial minorities, "friendships of solidarity" might actually be more essential to positive mental health outcomes (Harven 2014; Smith 2013; Durkee and Williams 2015). Such friendships provide a safe space to discuss experiences of racial discrimination, thus serving to buffer the stress that discrimination creates for racial and ethnic minorities (Harven 2014; Pearlin 1989). This study is motivated by the need to understand how the demographic characteristics of one's friends might influence the association between friendships and mental well-being. It is also motivated by the lack of unity in the literature with regards to the impact of racially different friendships for racial minorities. Lastly, these questions grow in importance as the United States continues to grow racially and ethnically diverse (Census 2010). Such an increase in diversity nationally might also lead to more racially heterogeneous friendships. Sociologists should explore how these shifts might influence the mental health of adolescents who in many ways rely on strong peer networks to better understand their own identity. 
This study seeks to understand how racial differences within friendship networks might moderate the effect friendship in adolescence has on mental well-being. This study will add to the current body of literature on friendships in the stress process by identifying how race interacts with social support and asking why varying types of friendship might lead to more or less mental well-being in adolescents. By performing a secondary data analysis using data from The National Longitudinal Study of Adolescent to Adult Health (Add Health), this research will explore how having a racially diverse friendship network might alter the positive association between friendships and mental well-being. Few studies have investigated the role the race of friends might play within the stress process, but the sociology literature on friendship does show that friendships can have a varying effect on mental well-being based on an individual respondent's race (Harven 2014; Corona et al 2017; Mossakowski and Zhang 2014). Thus, I will also investigate how the strength of the association between racially diverse friendship networks and mental well-being varies for Asian, Latino, Black, White, and "other race" adolescents. In order to reach these goals, I ask the following two research questions: Do racially diverse friendship networks affect adolescent mental well-being? Does the race of the respondent moderate the effects of racial diversity in friendship networks on mental well-being? 


\section{Chapter 2: Literature Review}

In order to better understand the role of race and friends on mental health, I draw upon two theoretical frameworks: Leonard I. Pearlin's Stress Process model and Gordon Allport's Contact Theory.

\section{Pearlin's Stress Process}

Leonard I. Pearlin provides a theoretical framework for the social factors that contribute to high stress and poor mental health, including aspects of mental health such as mental-well being (Pearlin 1999). Pearlin's "stress process" begins with a stressor: any condition that has the potential to "upset adaptive capacity." Three moderating resources — social support, coping, and mastery—are employed in response to these stressors in an attempt to protect a person from the harms of stress. This study examines the "social support" moderating resource, as friendships are one form of social support. As a resource, social support from friends, family, etc., means an individual can rely on people to alleviate stress in some way (economic support, emotional labor, etc.) (Turner 1999).

Moderating resources, including friendships, can have both main effects and buffering effects (Pearlin 1999; Turner 1999). A main effect is one that directly impacts a stress outcome, regardless of the level of experienced stress; this is the type of effect focused on in this study (Pearlin 1999). For example, strong social support can lead to better mental health regardless of whether or not an individual needs to rely on that social support at the given time. A buffering effect is one that is triggered in times when a person is exposed to more intense stress (Pearlin 1999). For social support factors, this 
might mean the person is able to come to friends for advice in a time of need or gain financial assistance when struggling economically. The third part of the "stress process" is the outcome. An outcome is any end condition that results from the association between a stressor and a moderator (Pearlin 1999). Outcome variables can include physical health ailments, but mental health outcomes like depression and anxiety are studied more often in the available literature (Pearlin 1999). Mental well-being is one such measured outcome (Beiser 1974; Hughes et al 2014; Thoits and Link 2016). Allport's Contact Theory

Contact Theory proposes that intergroup contact reduces prejudice against outgroups, including but not limited to racial minorities (Allport 1954; Pettigrew 1998). Contact theory was first coined and developed in response to decreased levels of prejudice and increased mutual respect among interracial groups of soldiers after World War II (Pettigrew 1998). However, the ability for intergroup contact to improve relations between in-groups and out-groups is most salient when the contact achieves four conditions. Equal status (1) in intergroup contact places all parties on the same playing field rather than attaching a hierarchy that might be present in, for example, the relationship between a student and teacher. Common goals (2) and intergroup cooperation (3) are also essential, as they both ensure that the people within the group must work together to achieve some end. Lastly, more successful positive effects come out of intergroup contact if the group operates with support from authorities, law, and custom (4). This makes the intergroup contact normative as opposed to being treated as a single situation. The four conditions of intergroup contact are important to understand, as 
ignoring them could lead to incorrect assumptions about what types of intergroup contact lead to better racial attitudes (Pettigrew 1998). Intergroup contact also develops with time, as it takes sustained positive contact with an "out-group" for the individual to begin generalizing positive racial attitudes to the group and re-framing their own racial identity (Pettigrew 1998).

Although this study is not centrally concerned with racial attitudes, such attitudes do contribute to the mental health outcomes of adolescents (Harven 2014; Hughes et al 2014). Additionally, interethnic and interracial friendships can act as a proxy for the sustained, equal status contact mentioned in contact theory. An investigation of contact theory and how it might connect to the stress process is of central interest in this thesis.

\section{Mental Well-Being}

Mental well-being is a general measure of a person's ability to cope with stress and realize their potential, thus enabling them to live a satisfied life (Proctor et al 2010; Beiser 1974). Well-being is also often divided into "subjective well-being" and "psychological well-being" (Thoits and Link 2016). This thesis looks specifically at psychological well-being, which includes components of positive mental health (i.e.: sense of control, self-esteem) and the level of experienced emotional distress (Thoits and Link 2016). So, in order to assess psychological well-being, one must explore both social illnesses like depression and anxiety and the qualities that might buffer the prevalence of such illnesses, such as self-esteem and a sense of control (Thoits and Link 2016). 
Mental well-being is correlated with both interpersonal variables (empathy, strong peer bonds) and interactive variables (socially participant behavior, hobbies) (Beiser 1974). The self-esteem and life satisfaction reflected by mental well-being are also highly related to achievement and happiness (Beiser 1974; Thoits and Link 2016; Proctor and Maltby 2010). As such, poor mental well-being suggests not only an inability to cope with stress and low satisfaction but also a depressed mood. Adolescents who report high mental well-being also report higher academic achievement, higher overall well-being, and better peer relationships (Proctor and Maltby 2010). The benefits of high mental well-being continue beyond adolescence and are essential for adolescents' growth into happy, satisfied adults (Proctor and Maltby 2010).

\section{Friendship}

Friendships are an interpersonal relationship that contributes to the mental wellbeing of an individual (Easterbrook and Vignoles 2015). Like other social support resources, friendship has both a main effect and buffering effect within the stress process (Turner 1999). One empirical example of a main effect comes from studies of college dormitories: Places that are better able to help friendships manifest tend to have residents that report more positive mental well-being in comparison to people living in solitary spaces, regardless of the level of psychological distress (Easterbrook and Vignoles 2015). Buffering effects include adolescents turning to friends after experiencing prejudice at school (Ueno 2009; Harven 2014).

Friendships themselves have significant variation. For example, there is a difference between a "weakly tied" friendship and a "strongly tied" friendship (Kivijarvi 
2015; Knifsend 2013). A "weakly tied" friendship is one that is not sustained outside of a point of contact such as an after school sport center (Kivijarvi 2015). A strongly tied friendship goes beyond the point of shared activity. Kivijarvi thus points out the importance of differentiating between close and casual friendships. For example, such "weakly tied" friendships may not lead to the same positive mental health benefits as a "strongly tied" friendship or a best friendship, a term that implies a degree of exclusivity in comparison to other friends.

\section{Race and Friendship}

The positive effects of friendship vary across demographics. For example, one study found that while strong friendship networks are important for blacks coping with the negative effects that racial discrimination can have on educational outcomes, strong parental educational advocacy was more important than friendship for Latinos (Harven 2014). This may be in part due to familismo, a term describing the tight-knit structure of many Latino families (Corona et al 2017). The cultural importance of family among many Latinas/os serves as a key mediator of stress resulting from both discrimination and acculturation (Corona et al 2017). This is not to say that other racial minorities do not need strong family support, but rather that Hispanic and/or Latina/o populations rely on family support more often (Corona et al 2017).

There is some evidence that social support is not as effective a mediator for Asian Americans when it comes to the ability to counter stress from discrimination (Mossakowski and Zhang 2014). Although social support likely plays some role in buffering stress among Asians, Asian people do not express their "worries" about 
discrimination to friends and family as frequently as members of other racial groups do. It is possible that Asian people believe these stressors to be personal problems rather than group issues. Alternatively, they may feel coming to family or friends with concerns that they do not perceive as severe places an unnecessary burden on people other than themselves (Mossakowski and Zhang 2014). The hesitation to confide in friends and family in times of increased stress is likely related to the fact both Asians and AsianWhite biracials report lower self-esteem and, in some studies, higher prevalence of depressive symptoms (Doyle 2007). Such a connection would be expected in the stress process because if people are unwilling to confide in friends and family, then these resources are also buffering less stress (Pearlin 1999; Turner 1999). Other studies do show, however, that among many Asian ethnic groups (Vietnamese, Chinese, Koreans, to name a few), same-ethnic social support can buffer against stress (Mossakowski and Zhang 2014; Noh and Kaspar 2003; Tummala-Narra and Sathasivam Rueckert 2016). Research shows that immigrants face significant stress from "acculturation," the process of cultural change that results when two different cultures are in contact with one another (Tummala-Narra and Sathasivam Rueckert 2016; Corona et al; Mossakowski and Zhang 2014) . Children tend to acculturate faster than their parents, which may in part explain why parents are a less effective social support resource in comparison to samegeneration peers (Tummala-Narra and Sathasivam Rueckert 2016). Children may view their parents as too far removed from their experiences to understand the stressors they are experiencing. For example, immigrant children often express a desire to fit in with racially or ethnically different peers, something parents may be resistant to (Tummala- 
Narra and Sathasivam Rueckert 2016). Asia is the second largest birth region for U.S. immigrants, and Asians are the fastest-growing U.S. race group (United States Census 2010). Because many Asians are from families that recently immigrated, this acculturation stress might partly explain differences in the use of social support as a coping resource.

Measures of relational mobility may also explain the difference in the importance of social support from friends (Kosuke et al. 2014; Zhang and Li 2014). Relational mobility is the ability to find new social circles if one feels they must leave their current social circle. In comparison to people in the United States, people living in Asia have much lower relational mobility, which contributes to social circles remaining intact over time but also an increased anxiety related to a potential loss of friends (Kosuke et al. 2014; Zhang and Li 2014). This anxiety leads to a minimization of situations in which they can be rejected by their friend group. This would include choosing not to seek emotional assistance in times of high stress (Kosuke et al. 2014; Zhang and Li 2014). Because friends are not sought out in times of increased stress, they become less effective at buffering experienced stress. Relational mobility remains low for Asian migrants, although it does increase as they begin to adapt to the new culture (Zhang and Li 2014). Relational mobility likely contributes to the mental health disadvantage many Asians face (Doyle 2008) .

\section{Friendships of Difference}

Differences in the racial heterogeneity or homogeneity of the friend group also change the relationship between friendship and mental health. These differences often 
lead to somewhat contradictory findings on the importance of the race of one's friends on predicting mental well-being. The first body of literature, which I define as supporting the "friendship of difference" hypothesis, suggests that racially diverse friendship networks, over time, might lead to better mental health outcomes for adolescents. The "friendship of difference" orientation includes studies of contact theory and prejudicerelated stress.

Interracial friendships within schools are a key interest among contact theorists and have proven to be a strong predictor of racial attitudes (Powers and Ellison 1995). Such friendships reveal that the positive effects of intergroup contact are cumulative. The change in prejudicial attitudes is unlikely to happen due to a single positive experience with an out-group member that counters stereotypes of that group. In fact, initial intergroup contacts can often be filled with anxiety regardless of the preconceived attitudes toward the racial group in question (Pettigrew 1988). Perceived threat also impedes both contact itself and the potential positive effects of intergroup contact. Such prejudicial experiences can have long term impacts on the mental health of minorities (Soto et al 2016; Thoits and Link 2016). For example, students who encounter more negative racial experiences in high school tend to transition poorly into colleges, which are often predominantly white institutions (Soto et al 2016). In other words, if intergroup contact does not consistently meet the four conditions of contact theory and fails to be "positive contact," then minorities often face increased stress in racial environments that are predominantly white (Soto et al 2016). 
Stigma and prejudice can be strong stressors for minority groups (Thoits and Link 2016; Tummala-Narra and Sathasivam Rueckert 2016). Intergroup contact may eventually lead to better racial attitudes but also lead to increased exposure to prejudice in the short term (Tummala-Narra and Sathasivam Rueckert 2016; Pettigrew 1988; Ueno 2009). Establishing long-term quality friendships with out-group people overtime leads to diminished out-group prejudice, reappraisals of in-group culture as the "correct" way to live, and a resulting acceptance of not only the friendship but other out-group members (Pettigrew 1988). In support of this, immigrant minority youth show a conscious desire to connect with in-group peers in order to not only feel more belonging in the mainstream culture but also to challenge stereotypes their peers might have of them (Tummala-Narra and Sathasivam Rueckert 2016). Ultimately, it is a possibility that the decrease in racial anxiety, a net-decrease in prejudice, and an increased sense of belonging for out-group members lead to more positive mental health outcomes.

Racially or ethnically heterogeneous friendships tend to have weak ties, whereas racially or ethnically homogeneous friendships tend to have stronger ties (Kivijarvi 2015; Tummala-Narra and Sathasivam Rueckert 2016; Kao and Joyner 2005). "Best friend" pairings are more likely to be from the same ethnic group (Kao and Joyner 2005). "Best friend" pairs demonstrate more time participating in shared activities in comparison to other friends within a friendship network, which suggests, then, that same-ethnic friendships are tied to higher friendship intimacy (Kao and Joyner 2005). Because the race or ethnicity of a friend and the strength of a friendship seem to be tied together, further research is necessary to determine if this relationship also results in a difference in 
mental health outcomes. Regardless, weak heterogeneous friendship ties still have positive benefits for minority youth (Kivijarvi 2015; Knifsend 2014). They can lead to increased feelings of belonging in school—a key interpersonal factor related to mental well-being in adolescence - and more positive attitudes toward people of different backgrounds (Knifsend 2014; Proctor et al 2010; Tummala-Narra and Sathasivam Rueckert 2016). In other words, although these interracial friendships may be considered weaker friendships or of lower quality, they are still a source of social support than can influence the stress process.

Interracial romantic relationships have similar results, with couples reporting increased instability and stress from a loss of support and cultural difference, but also a "spousal health advantage" for minorities married to white spouses (Miller and Kale 2016; Yancey 2007). Minorities who marry whites are able to gain access to groups and social institutions generally closed off to them (Miller and Kale 1016). Interracial friendships may provide similar access to resources if the friendship becomes a "strong tie" after cumulative, positive intergroup contact (Kivijarvi 2015; Pettigrew 1998). There is some support from this in literature on the influence of diversity in peer groups on educational attainment, as minority students are more likely to graduate if they attend schools with higher rates of diversity in enrollment (Goza and Ryabov 2009; Ryabov 2011).

Support for the friendship of difference hypothesis is also present in studies of other demographic characteristics. The literature on sexual orientation and the gender heterogeneity of friendship net works suggests that friendships of difference are more 
essential to the mental well-being of sexual minorities than are friendships of solidarity (Baiocco et al. 2014).

\section{Friendships of Solidarity}

The second set of findings in the literature point to the importance of strong relationships with same-race friends in predicting mental well-being. Some racial minorities seem to benefit more from homogenous friendships, especially if they perceive high levels of prejudice within their schools.

Racial identity has been shown to moderate the impact of stressors on mental health (Hughes et al 2014). This points to the importance of studying race as a variable within the stress process. Much of the available research only looks at mental health outcomes that result from the experience of racial prejudice or stigma. However, Hughes, Kiecolt, and Keith (2014) show that financial stress, a stressor that is not explicitly racial, is impacted by racial identity. Racial identity, measured through the closeness to one's racial group and the evaluation of that group, is a buffer within the stress process that protects mental health by boosting other psychological resources (Hughes et al 2014). "[It] connects people to others via meaningful social roles in their families and communities, and it enhances self-esteem and mastery" (Hughes et al 2014: 39). Selfesteem and mastery are two central measures of psychological well-being. If closeness to one's racial group enhances psychological resources, then it might follow that the presence of same-race friends are important for protecting adolescent mental health through the same avenues. This relationship might be especially important for African Americans, who have as a group experienced intense historical discrimination. 
Historically, black communities in the United States were compelled to create new avenues of social and economic resources for black individuals in response to severe racial oppression (Hughes et al 2014; Hill Collins 2000). This history of providing community resources and the building of minority networks may in part explain the importance of racial identity as a stress buffer for black individuals. Other racial and ethnic minorities might live in communities that facilitate the creation of similar minority networks, but the history of black racism within the United States and the continued prevalence of black prejudice contributes to the uniqueness of black-identified people in studies examining racial differences within the stress process (Noh and Kaspar 2003; Hughes et al 2014).

Black identification among adolescents also points to unique variations in the importance of friendship as a buffer. Black students seem to be better equipped to overcome the stress caused by discrimination if they have strong friendship networks (Harven 2014). This is especially true if those friends are of the same race; such friendships of solidarity allow for a safe space in which people can discuss their experiences (Harven 2014; Ueno 2009; Hill Collins 2000). In turn, the ability to overcome the stressors of discrimination are related to academic achievement and mental well-being (Harven 2014; Ueno 2009). Schools where more same-race peers are present also increases school attachment because of the lower rates of experienced prejudice for all minority groups, but especially black youth (Ueno 2009). Self-esteem increases as a result of the lower rates of discrimination in more racially homogeneous schools (Ueno 2009). Thus, although establishing friendships is important for all youth, friendships of 
solidarity seem especially important for black youth who often face harsher prejudice and greater disadvantages within the United States. Immigrant populations—-black and nonblack - also seem to rely on same-race or same-ethnic friendships to cope with experiences of discrimination and acculturation stress even though they also express a desire to connect with in-group friends (Tummala-Narra and Sathasivam-Rueckert 2016).

Multi-racial and multi-ethnic friendships may actually cause increased stress despite the fact that people with more of them are better able to see things from perspectives that are not their own (Smith 2013). For example, black students reported more severe mental health symptoms and lower racial identity if they were frequently accused of "acting white" by their peers (Durkee and Williams 2015). The racial make-up of peer groups is one factor that leads to these accusations.

More homogeneous friendship networks also provide "ethnic social capital," which give them access to cultural resources that contribute to academic achievement and educational attainment (Goza and Ryabov 2009; Noh and Kaspar 2003). The impact of homogeneous peer networks seems somewhat contradictory, however, and seems most salient for Asian and Latino youth—not black youth (Goza and Ryabov 2009; Ryabov 2011). Black youth are also unique in that they have higher success when they are in more segregated schools and when they have more diverse friendship networks (Goza and Ryabov 2009; Ryabov 2011).

Other types of social support, such as support found in romantic relationships, might allow us to better predict the importance of race of friends on determining mental well-being. Studies examining social support from romantic relationships mostly supports 
the "solidarity" hypothesis. Even though these relationships lead to changes in racial attitudes within the pair, prejudice, stigma, and cultural differences lead to increased stress and diminished well-being (Burke 2015; Bratter and Eschbach 2006; Miller and Kale 2016). Interracial couples often face more instability in their relationships because of lower support from family, friends, and co-workers in addition to the added stressors of discrimination and cultural difference (Burke 2015; Bratter and Eschbach 2006). Much of the "burden" of interracial relationships falls on white women, who face increased exposure to discrimination through their minority male partners but do not necessarily have the coping mechanisms to combat the stress that results from it (Bratter and Eschbach 2006; Miller and Kail 2016). If social support from friendships acts similarly to that provided by romantic relationships, then interracial friendships might lead to a similar increase in stress from experienced prejudice that accompanies a growing racial awareness. Racially privileged members of a friendship network thus might face declines in mental well-being because the race of their friends increases the likelihood that they themselves encounter prejudice, albeit indirectly.

Although the literature suggests that the importance of friendship varies depending on both the race of the participant and the heterogeneity of the friend group, it also points to the need to test this conclusion empirically. Many studies reserve a discussion of racial difference in friendship networks to the limitations section of their studies rather than attempting to test it. Friendship should not be treated as a monolithic moderating effect on the stress process. Social status affects both the availability of social support and exposure to stress (Turner 1999). In addition to exploring how social status 
moderates the stress process, research needs to explore variation within social support itself. Race — a factor in determining social status - might also lead to changes in the main effect of social support. Studies on contact theory, stigma and prejudice, and racial identity all point to a needed understanding of how the racial composition of a friendship network might change the overall effectiveness of friendships as a buffer in the stress process. Unlike coping and mastery, the other two primary moderating resources in the stress process, social support is primarily derived from other people. Although defined as a resource, people within a social network are not "blank slates" with the exact same functions or statuses as every other person within that network. People within social support networks have an inscribed social status and changing levels of stress. These conditions might change their own capacity to provide social support. This study seeks to explore this issue of social support by examining how friendships, diversity in friendship networks, and race might interact and lead to mental well-being.

Research Questions and Hypothesis

This research will answer the questions: Do racially diverse friendship networks affect adolescent mental well-being? Does the race of the respondent moderate the effects of racial diversity in friendship networks on mental well-being?

Based on the available literature, I hypothesize the following: Hypothesis 1a: Racial difference within an adolescent's friendship network will be associated with reduced mental well-being, as measured by depression symptoms and self-esteem. 
Hypothesis 1b: Racial difference within an adolescent's friendship network will be associated with increased mental well-being, as measured by depression symptoms and self-esteem.

Hypothesis 2: The association between racial difference within an adolescent's friendship network and mental well being will vary by the race/ethnicity of the respondent.

Hypothesis 1a was formed because there is more empirical support for the "friendships of solidarity" argument within the literature, especially in connection to the importance of racial identity. "Friendships of difference" likely still play a role, but may be more important in reducing racial attitudes than in impacting the mental health of adolescents. Hypothesis $1 \mathrm{~b}$ is a competing hypothesis that accounts for the possibility that "friendships of difference" are positively correlated to mental well-being. Nonetheless, more of the available literature supports hypothesis $1 \mathrm{~b}$. Hypothesis 2 covers the variations by respondent race found in the available literature. Respondents from various racial/ethnic groups likely rely on social support resources at different rates and in different circumstances. 


\section{Chapter 3: Data and Methods}

To test the hypotheses, I perform a cross-sectional secondary data analysis of survey data from The National Longitudinal Study of Adolescent to Adult Health (Add Health). The survey was initiated by the Eunice Kennedy Shriver National Institute of Child Health and Human Development in response to a U.S. Congress mandate to fund a study on adolescent health that focused on forces that might lead to poor health and risky behaviors. Data were gathered at the school level, and researchers used a systematic stratified sampling process in order to ensure a nationally representative sample that included variety in the geographic characteristics such as urbanicity and individual student characteristics such as the ethnicity. 132 schools in 80 communities were selected to participate. Selected schools were paired with a nearby school in order to allow a more thorough examination of network variables such as the friendship groups of adolescents. The survey follows students who were in grades 7-12 during the 1994-95 school year, the baseline year of the survey. Follow up data were collected in three subsequent waves, in 1996, 2001-02, and 2008. A fifth wave is scheduled to take place in 2016-18.

Wave I of the Add Health survey includes an in-school student questionnaire $(\mathrm{N}=90,118)$, an in-home student interview survey $(\mathrm{N}=20,745)$, and other questionnaires filled out by parents, siblings, students, and school administrators. Analysis is limited to Wave I because it is the only wave in which all respondents were adolescents, the life course stage of interest. The sample available in the public-use data set has a sample size of 6,504. The in-home survey is a stratified sample of those who took the in-school survey. It is the in-home survey that the available data on friendship networks was based 
on. However, the in-home survey has a smaller sample size, further restricting the available sample size. Along with respondents who are missing responses to key variables, the final sample size is 4,110 in linear regressions predicting adolescent mental health and 4,114 in linear regressions predicting adolescent self-esteem. Despite sample size limitations, Add Health is a unique data source that is well-equipped in answering my research questions. The available data are a large, nationally representative sample that ask many questions about the health of adolescents. The extensive attention to friendships in adolescence and mental health outcomes make Add Health an ideal data source for examining the moderating influence of the race of friends on the associations between friendship racial heterogeneity and mental well-being.

This study merges publically available data from the Wave I in-school student questionnaire, the in-home student interview survey, and the network data. Data were weighted using the grand sampling weight. The grand sampling weight was standardized to adjust for inflated t-values and oversampling (Chen and Chantala 2014). This is because adolescents in the sample did not have an equal chance of being selected for the in-home survey in order to ensure that the sample was nationally representative. The data analysis was performed using SPSS 24.

\section{Dependent Variables}

Mental well-being is generally measured by looking at multiple dependent variable characteristics that, when taken together, act as a proxy for overall life satisfaction (Thoits and Link 2016; Hughes et al 2014). These measures include scales of depression, self-esteem, and quality of life (Thoits and Link 2016). Some studies also 
include a measure of mastery to measure how much control a respondent feels over their own life. Wave 1 of AddHealth only includes measures of depression and self-esteem. However, the data that can be gathered through these scales allows us to approximate an adolescent's mental well-being. Later waves of AddHealth include measures of quality of life or life satisfaction, opening up opportunities for future longitudinal analysis. This research does not include these waves because the focus is on the importance of friendship in adolescence, not the years following it.

Dependent Variable 1: Mental Health (CES-D Depression Index)

The Wave I in-home survey data that asks a series of questions related to the feelings of respondents (See Appendix A, Table 9). These questions are from the Center for Epidemiologic Studies Depression Scale (CES-D). The CES-D is primarily used to measure depressed mood, but has questions that are related to other diagnoses, such as anxiety (Radloff 1977). CES-D is highly correlated with more direct measures of mental well-being (Yin et al 2013; CES-D). As such, it serves the goals of this research. The 19 items within the constructed scale ask respondents to document how they have felt in the last two weeks. Examples of these measures are "you were bothered by things that usually don't bother you" and "You had trouble keeping your mind on what you were doing" (See Appendix A, Table 9). Each item is measured on a four point scale: "never or rarely," "sometimes," "a lot of the time," "most of the time or all of the time." Items were reversed coded such that a high score represented a lower level of depressive symptoms. For ease of comprehension, I refer to the scale as one of mental health, although this does not intend to suggest that mental health is measured solely based on the amount of 
depressive symptoms one has. The items were indexed with values ranging from 0 , the poorest mental health score, to 50 , the best possible mental health score (alpha=.915). 
Dependent Variable 2: Self-Esteem (Modified Rosenberg Self-Esteem Scale)

Self-esteem, a key psychological resource that often reflects well-being, is measured by a 5 -item scale. Example items are similar to those of the Rosenberg 10-item self-esteem scale, including "you feel you are doing everything just about right" and "you have a lot of good qualities" (Rosenberg 1965). Each of the 5 items is measured on a 5point Likert scale ranging from "strongly agree" to strongly disagree" (See Appendix A, Table 9). The items were coded such that a higher value reflected higher levels of selfesteem and ranged from a value of 0 to a value of 30 (alpha $=.845)$.

Key Independent Variable: Racial Difference in Friendship Networks

AddHealth network data provides a scale of the racial difference within a respondent's friendship (See Appendix A, Table 9). Racial difference is measured by the percentage of reported friends that are of a different race than the respondent.

Respondents were asked to report the names of up to five male and five female friends, in order of closeness. A friendship quality index is included as a control in order to account for the potential impact of a "best friend" in comparison to other reported friends. If a reported friend was included in the available school network, consisting of their own school and a "paired" school within the same community, they were added to the friendship network dataset. These reported friends likely also took the survey (or at least the in-school portion), so their self-reported demographic data was available for inclusion in the social network data.

The social network data has two main limitations. Firstly, reported friends outside of the network could not be included. As such, the data cannot be generalized to include 
friendships that might be formed outside of school, such as friends from non-school extracurricular activities. Secondly, although I can determine racial difference in friendship networks, I cannot determine racial heterogeneity of the network. A white respondent with 4 Asian friends will have the same racial difference score as a white respondent with 2 Asian and 2 black friends. However, the available racial difference information is still expansive and provides a unique opportunity to examine the importance of friendships of solidarity or friendships of difference on the mental wellbeing of adolescents. Also, although I could potentially create a number of friends index variable with the available data, its validity in the analysis would be questionable because I cannot tell if the reported friend was included in the racial difference network variable.

Scores on the scale of racial difference range from 0 , representing complete racial similarity within the reported friendship network, to 1, representing complete racial difference. For example, if a white respondent reported 3 friends within their school network, which consists of their own school and a "paired" school within the same community, and one of these three friends is non-white, then their "friendship difference" score would be .33 . I recoded this scale by multiplying it by 100 . This allows me to interpret beta coefficients per 1 percent increases. The scale used for this study includes all friends a respondent perceived to be a friend. AddHealth has two other scales of racial difference - one that shows the race of friends that reported that respondent as a friend, and another that limits the network to include only reported friends that also reported the respondent as a friend. In order to avoid limiting the available friends and to reflect literature that suggests the perception of having a friend is more essential to the social 
support effect on stress than the reality of that friendship, the scale including both reciprocal and non-reciprocal friendships was selected (Turner 1999). 


\section{Demographic Characteristics}

Because this study is interested in understanding the differing associations between race, friendship difference, and mental well-being, controlling for demographic characteristics is necessary. I take data on reported demographic characteristics from the AddHealth in-school questionnaire. The questionnaire creates dichotomous race variables for Black, White, Asian, Native American, and "Other" race respondents as well as a dichotomous ethnicity variable for hispanic or non-hispanic (See Appendix A, Table 10). Each dichotomous variable is a simple "yes" or "no" response.

Asian respondents only make up about $6 \%$ of the sample, but were kept as a separate category because of the potentially unique relationship between race and the dependent variables ( $\mathrm{N}=173$ for CES-D; $\mathrm{N}=175$ for Self-Esteem). White identification is included as a reference category in the linear regression models. The variable for Hispanic respondents is coded as an ethnicity variable. As such, interpretation of the Hispanic variable's relationship with the racial difference in friendship network variable is different than that of the race variables. A White-Hispanic's racial difference score would show the percentage of friends that are non-white. In other words, the racial difference of friendship networks for a Hispanic respondent does not measure if their friends are also Hispanic.

Respondents who self-reported as Native American or "other" race were collapsed into a new "other" category ( $\mathrm{N}=362$ for CES-D; $\mathrm{N}=359$ for Self-Esteem). Crosstabs reveal that most of the adolescents who identified as "other" were either of Hispanic ethnicity or Native American. Of the 647 adolescents who identified as "other" in the 
public-use AddHealth wave 1 data, 36\% (n=236) were Native American, and 61\% $(n=397)$ were Hispanic. Although not a perfect measurement of the "ethnic difference" in friendship networks among Hispanic adolescents, it does provide some insight into whether or not ethnic difference is a predictor of mental well-being for Hispanics. Not all Hispanics identify as "other" race, however. Of the Hispanic population in my sample, $52 \%(n=383)$ identified as white and $48 \%(n=350)$ identified as "other" race (See Appendix B, Table 12).

Biological sex is also included as a control variable, as there are unique relationships between sex and mental health outcomes. Moderator: Race X Racial Difference of Friendship Networks.

Interaction variables test hypothesis 2 by checking if the relationship between racial difference in friendship networks and mental well-being is unique for specific racial identities. In order to create an interaction effect between the race of the participant and the racial diversity within their friendship networks, I multiply the dichotomous race variables and the Hispanic variable with the racial difference of friendship network percentage variable. As such, any respondent who does not mark themselves to the race or ethnicity variable in question or has zero friends of a different race in their network is assigned a score of zero in the moderator. This allows us to look specifically at the association between racial difference and mental well-being for the race or ethnic group in question. The interaction variables are the central interest of hypothesis 2 . Research suggests that variations in the stress process often occur based on demographic characteristics (Pearlin 1989). In the case of the role of friendships, research suggests that 
same-race friendships might be more significant for black adolescents, who often experience more prejudice (Harven 2014; Durkee and Williams 2015; Smith 2013). Latino adolescents tend to rely more on familial social support than the support of their friends, and Asian adolescents seem to rely less on social support as a resource as a whole unless the psychological distress they are facing is perceived as severe or beyond a "personal problem" (Mossakowski and Zhang 2014; Corona et al 2017). Looking at the racial difference within a friendship network adds to the literature by finding out if who an adolescent is friends with matters.

\section{Controls}

Controls added to the linear regression models were selected based on the available literature on mental well-being and friendship. Biological sex was included, but AddHealth has no measure for the gender or sexual orientation of reported friends. Other controls include factors shown to have significant associations with mental well-being: friendship quality (alpha $=0.825)$, participation in hobbies, relationship with parents (alpha=0.606), general health, and perceived prejudice (see Appendix A, Table 11). Each of these controls is based on evidence of their significant relationships with mental wellbeing and friendships.

I constructed a friendship quality index that measures closeness to best friends to account for potential differences between "weak-tie" and "strong-tie" friendships (Kivijarvi 2015). Relationship with parents is another social support variable that not only influences and mediates adolescent mental well-being but also has effects that vary by race (Pearlin 1999; Harven 2014; Corona et al 2017; Mossakowski and Zhang 2014). 
Additionally, increases in psychological distress as a result of diminished family support in response to being in an interracial romantic relationship have been cited in some research (Burke 2015; Bratter and Eschbach 2006). A similar relationship may occur for adolescents with different-race friends. "Relationship with parents" is a constructed variable that takes the mean response to two questions that ask "Overall, are you satisfied with your relationship with your mother?" and "Overall, are you satisfied with your relationship with your father?" (alpha $=0.606$ ). Combining these two variables into a "relationship with parents" mean index allows for the inclusion of adolescents with single parents.

Hobbies are included as a measure of the "interactivity" often correlated with higher mental well-being because they can bring about a sense of accomplishment (Beiser 1974). However, hobbies can vary based on how much skill they require to accomplish and how "social" they are (Beiser 1974). These differences are not captured by the hobbies control variable. Mental well-being is also often associated with general self-reported health (Proctor et al 2010). The control for prejudice is key to this analysis because of the competing "friendships of difference" and "friendships of solidarity" hypotheses. Intergroup contact may ultimately lead to better racial attitudes but also expose people to more prejudice in the short term (Allport 1954; Pettigrew 1988; Powers and Ellison 1995). Groups who perceive more prejudice may also have more of a need for same-race friends with which they can discuss and process the prejudice they have experienced (Harven 2014; Tummala-Narra and Sathasivam Rueckert 2016; Soto et al 2016; Hill Collins 2000). The Add Health measure for perceived prejudice asks "How 
much do you agree with the following statement? Students at your school are prejudiced." This measure does not distinguish between racial prejudice and other types of prejudice, nor does it ask if the prejudice is directly experienced by the respondent. As such, the claims made about the relationship between prejudice and mental well-being are more general, and I cannot conclusively say from my data that the experiencing racial prejudice changes the relationship between racial difference in friendship networks and mental well-being.

\section{Figure 1: Concept Map of Hypothesized Relationships between Variables}
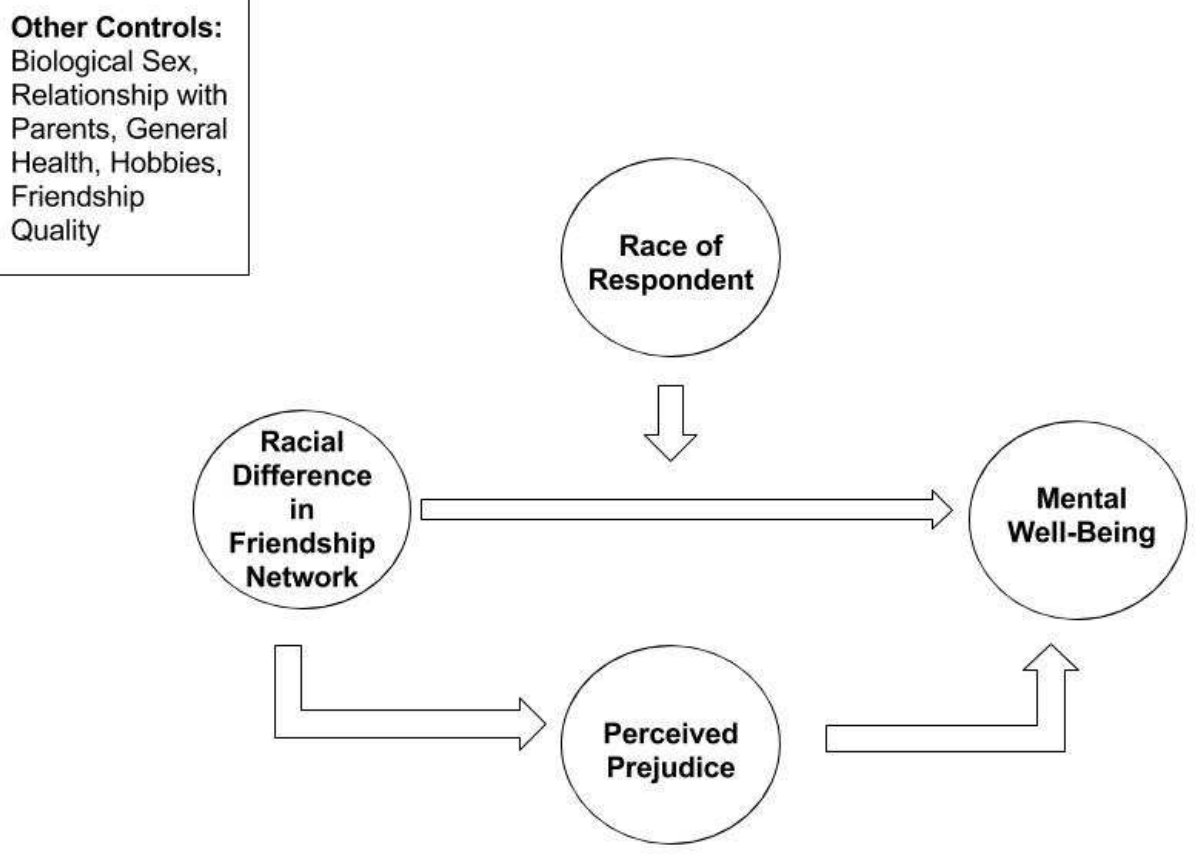


\section{Analytic Plan}

Figure 1 shows a concept map of the expected relationships between variables. In the model, there is a direct line between the "racial difference in friendship network" and mental well-being. This constitutes a "main effect" in the stress process model. This main effect is moderated by the race of respondent. The arrow on the bottom illustrates how I expect there to be a mediating influence from the amount of prejudice that the respondent perceives his or her peers to have. I do not expect the relationship to be fully mediated by perceived prejudice.

Linear regression analysis of Wave I Add Health data is appropriate for answering my research questions because it examines the relationship between racial difference in friendship networks and mental well-being during adolescence. The data are better fit for linear regression, as the dependent variables are scales with large ranges. Assumptions of linear regression were also tested. The dependent variable measures for mental health and self-esteem are negatively skewed, which is expected. Most mental health measures have a negative skew if the sample is healthy. In order to account for this, I ran models with cubed dependent variables, then exponentiated the coefficients. Cubing variables corrects negative skews by creating a more normal distribution that is easier to interpret. These models did not lead to any substantively different findings. I then ran scatterplots of the bivariate relationships between the two dependent variables (mental health and selfesteem) and the key independent variable, racial difference in friendship networks. Scatterplots provide a visual test of linearity between variables as well as homoscedasticity (equal or similar variance of residuals). The scatterplot suggests 
homoscedasticity, but the large amount of data points makes it difficult to confirm linearity. This is discussed in my limitations.

To test the hypotheses, I first estimate a baseline model that shows the main association between racial difference of friendship networks and mental health (here measured with higher coefficients signifying lower amounts of depressive symptoms) and self-esteem, the two measures used to reflect mental well-being of adolescents (Table 3, Models 1-3; Table 6, Models 1-3).

$$
\begin{aligned}
& \text { Equation 1: Mental Health }=b_{1}+b_{2}(\text { racial difference })+ \\
& \text { control variables }+ \text { error. } \\
& \text { Equation 2: Self-Esteem }=b_{1}+b_{2}(\text { racial difference })+ \\
& \text { control variables }+ \text { error. }
\end{aligned}
$$

The analysis based on this equation verifies whether or not the hypothesis that racial difference will be associated with lower mental health and self-esteems scores, is supported. A significant association in just one of the two equations will provide partial support for the hypothesis.

I then test if the race of the participant moderates the association between racial difference in an adolescent friendship network and the two dependent variables, testing hypothesis 2 (Table 3, Model 4; Table 6, Model 4)

$$
\begin{aligned}
& \text { Equation 3: Mental Health }=b_{1}+b_{2}(\text { racial difference })+ \\
& b_{3}(\text { race X racial difference })+\text { control variables }+ \text { error. } \\
& \text { Equation 4: Self-Esteem }=b_{1}+b_{2}(\text { racial difference })+ \\
& b_{3}(\text { race } X \text { racial difference })+\text { control variables + error. }
\end{aligned}
$$


If any interaction variable within the full linear regression models predicting mental health and self-esteem, respectively, is determined to be significant, I then provide a supplemental linear regression analysis examining the significant interaction in more detail (Table 4-5; 7-8; Appendix B, 14-19). 


\section{Chapter 4: Results}

Table 1 shows descriptive statistics of variables in my analysis. The high mean on the mental health scale (39.07) suggests that most adolescents in the sample report experiencing depressive symptoms "sometimes" or "never or rarely." Similarly the mean on the self-esteem scale (24.76) is close to the score if a respondent marked "agree" to all 6 measures within the scale, meaning most adolescents report high self-esteem. Averages on the controls added based on evidence of their significance in the literature were also high and reflect a relatively healthy sample. The average diversity within a friendship network was $26 \%$. In other words, an average adolescent reports that one quarter of their friends are of a different race than they are. However, the t-tests in Table 2 show that this mean is primarily reflective of white respondents, who report the lowest amount of racial difference in friend groups (23\%) and make up $67 \%$ of the sample. Those identifying as "Other", who make up only $8 \%$ of the sample, reported having the most racially diverse friendship groups (41\%). This might be partly due to the lack of racially similar friends within their schools. Similarly, Asians make up only (4\%) of the sample and report that $40 \%$ of their friends are not Asian. White respondents, my reference category, also reported the highest average mental health scores (39.6). Black respondents reported the highest scores on self-esteem measures (25.5). Asian identifying adolescents reported the lowest mental health average (37.02) and self-esteem (23.7). Significance in t-tests (marked by asterisks in table 2) means that the differences in means are unlikely to be due to chance. 
Table 1: Descriptive Statistics

Std.

Mean Range Deviation Skewness Kurtosis N

Mental Health Scale (CES-D

Reversed)

Self-Esteem Scale

$39.07[0,50] \quad 7.52 \quad-1.14(.03) \quad 1.62(.06) 6457$

$24.76[6,30] \quad 3.53 \quad-0.57(.03) \quad 0.60(.06) 6467$

Racial Difference

Black

$26.47[0,76] \quad 22.20 \quad 0.20(.04) \quad-1.22(.08) 4243$

Asian

$\begin{array}{llll}0.25[0,1] & 0.43 & 1.16(.03) & -0.66(.06) 6485\end{array}$

$0.04[0,1] \quad 0.20^{\prime} \quad 4.59(.03) \quad 19.08(.06) 6485$

Other

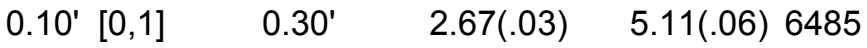

Hispanic

$\begin{array}{llll}0.11[0,1] & 0.32 & 2.42(.03) & 3.86(.06) 6481\end{array}$

Biological Sex (Female=1)

$0.56[0,1] \quad 0.50^{\prime}$

$-0.06(.03) \quad-1.99(.06) 6503$

Relationship with Parents

$3.22[0,4]$

0.84

$-1.36(.03)$

2.13(.06) 6363

General Health

$2.89[0,4]$

0.90 .

$-0.46(.03) \quad-0.42(.06) 6496$

Hobbies

$1.46[0,3]$

1.07

0.13(.03) - -1.23(.06) 6497

Friendship Quality

$0.44[0,1]$

0.31

0.13(.04) - -1.07(.07) 4751

Prejudice

$3.09[1,5]$

1.21

$-0.06(.03) \quad-1.00(.06) 6347$

Black*Racial Difference

$5.60[0,76]$

15.13

2.68(.03)

6.06(.06) 5989

Asian*Racial Difference

$1.11[0,72]$

7.40

6.91(.03) 47.98(.06) 6393

Other*Racial Difference

$2.41[0,76] \quad 11.05$

4.27(.03) 20.63(.06) 6200

Hispanic*Racial Difference

$2.81[0,76] \quad 11.93$

$4.27(.031) \quad 17.28(.06) 6124$

Table 2: T-Tests of Key Variables and Demographic Characteristics

Demographic

Characteristics (\% in final sample)

White (67\%)

Black (27\%)

Asian (4\%)

Other (8\%)

Hispanic (9\%)

Female

Male

$*(p \leq 0.05),{ }^{* *}(p \leq 0.01),{ }^{* * *}(p \leq 0.001)$

Means

$429439.6^{\star * *}$

$161938.5^{*}$

$270 \quad 37.02$

$64937.2^{* *}$

$743 \quad 37.4^{*}$

$335638.2^{\star \star *}$

$3147 \quad 39.9$
T-Test on Mental T-Test on Self

Health Scale: $\quad$ Esteem Scale:
T-Test on Racial

Difference in

Friendship Network: Means

24.7

25.5

23.7

24.2

$24.4^{\star *}$

24.4

25.3
Mean \%

$23.4 \%$ **

$30.0 \%$ *

$40.2 \%$ ***

$41.3 \%$

$45.2 \%$ ***

$26.8 \%$ *

$26.1 \%$ 
Table 3: Linear Unstandardized Coefficients from Linear Regression Models PredictingAdolescent Mental Health

\begin{tabular}{|c|c|c|c|c|}
\hline \multicolumn{5}{|l|}{ Dependent Variable: CES-D } \\
\hline & $\begin{array}{l}\text { Model } 1 \\
\text { B }\end{array}$ & $\begin{array}{l}\text { Model } 2 \\
\text { B }\end{array}$ & $\begin{array}{l}\text { Model } 3 \\
\text { B }\end{array}$ & $\begin{array}{l}\text { Model } 4 \\
\text { B }\end{array}$ \\
\hline \multirow[t]{2}{*}{ (constant) } & 40.119 & 41.129 & 30.305 & 30.558 \\
\hline & $(0.176)$ & $(0.217)$ & $(0.668)$ & $(0.677)$ \\
\hline \multirow[t]{2}{*}{ Racial Difference } & $-0.024^{* * *}$ & -0.009 & $-0.011^{*}$ & $-0.021^{* \star *}$ \\
\hline & $(0.005)$ & $(0.005)$ & $(0.005)$ & $(0.006)$ \\
\hline \multirow[t]{2}{*}{ Black } & & $-0.766^{* *}$ & $-1.431^{* * *}$ & $-1.884^{* * *}$ \\
\hline & & $(0.260)$ & $(0.246)$ & $(0.387)$ \\
\hline \multirow[t]{2}{*}{ Asian } & & $-2.615^{\star * \star}$ & $-2.194^{\star \star *}$ & $-6.167^{* \star *}$ \\
\hline & & $(0.573)$ & $(0.525)$ & $(1.150)$ \\
\hline \multirow[t]{2}{*}{ Other } & & $-1.553^{* * *}$ & $-0.992^{*}$ & -1.671 \\
\hline & & $(0.476)$ & $(0.436)$ & $(0.862)$ \\
\hline \multirow[t]{2}{*}{ Hispanic Origin } & & $-1.521^{* * *}$ & $-1.370^{* *}$ & -1.218 \\
\hline & & $(0.478)$ & $(0.438)$ & $(0.985)$ \\
\hline \multirow[t]{2}{*}{ Biological Sex } & & $-1.520^{\star \star \star}$ & $-0.633^{* *}$ & $-0.592^{* *}$ \\
\hline & & $(0.224)$ & $(0.211)$ & $(0.211)$ \\
\hline \multirow[t]{2}{*}{ Relationship with Parents } & & & $2.210^{\star * *}$ & $2.203^{\star * *}$ \\
\hline & & & $(0.126)$ & $(0.126)$ \\
\hline \multirow[t]{2}{*}{ General Health } & & & $1.815^{\star * *}$ & $1.816^{* * *}$ \\
\hline & & & $(0.119)$ & $(0.118)$ \\
\hline \multirow[t]{2}{*}{ Hobbies } & & & $0.442^{* * *}$ & $0.441^{* * *}$ \\
\hline & & & $(0.098)$ & $(0.098)$ \\
\hline \multirow[t]{2}{*}{ Friendship Quality } & & & 0.396 & 0.399 \\
\hline & & & $(0.350)$ & $(0.350)$ \\
\hline \multirow[t]{2}{*}{ Students are Prejudiced } & & & $-0.922^{* * *}$ & $-0.928^{* * *}$ \\
\hline & & & $(0.087)$ & $(0.087)$ \\
\hline \multirow[t]{2}{*}{ BlackRacial Difference } & & & & 0.017 \\
\hline & & & & $(0.011)$ \\
\hline \multirow[t]{2}{*}{ Asian*Racial Difference } & & & & $0.102^{* * *}$ \\
\hline & & & & $(0.026)$ \\
\hline \multirow[t]{2}{*}{ Other*Racial Difference } & & & & 0.019 \\
\hline & & & & $(0.020)$ \\
\hline \multirow[t]{2}{*}{ Hispanic Origin*Racial Difference } & & & & -0.002 \\
\hline & & & & $(0.022)$ \\
\hline Adjusted R-Square & 0.005 & 0.029 & 0.191 & 0.194 \\
\hline
\end{tabular}


Race, Race of Friends, and Mental Health

In order to answer my first research question, "do racially diverse friendship networks affect adolescent mental well-being?", I first tested if the racial difference within adolescent friendship networks was associated with higher mental health scores (Table 3). Mental health is the first of two measures I use to determine adolescent mental well-being. In the linear regression models predicting adolescent mental health, a significant negative association between the racial difference in friendship network variable and mental health scale would support hypothesis 1a, which states that racial difference within an adolescent's friendship network will be associated with lower mental well-being, as measured by level of depressive symptoms and self-esteem.

After examining the association net of controls in Table 3, Model 3, interactions between the race of participant and the racial difference in their friendship networks were added in Model 4 in order to test for possible variations in the association by race and ethnicity, which attempts to my second research question, "Does the race of the respondent moderate the effects of racial diversity in friendship networks on mental wellbeing?" If interaction terms are significant in either direction, then hypothesis 2 , which states that the association between racial difference within an adolescent's friendship network and mental well-being will vary by the race and ethnicity of the respondent, will be supported.

Table 3 shows coefficients from linear regression models predicting adolescent's mental health, here defined as lower levels of depression symptoms. The dependent variable is coded this way for ease of comprehension and does not intend to suggest that mental health is something that can actually be measured by the lack of symptoms of a 
single mental health condition. Model 1 shows the baseline relationship between racial difference and mental health without controls. Beta coefficients show the change that occurs for every one unit increase in the mental health scale, with higher scores representing lower levels of depression. For interpreting racial difference variable, the beta coefficient corresponds to a $1 \%$ increase in the racial difference of their friendship networks. An adolescent's mental health decreased by 0.024 units for a one percent increase in the racial difference within a friendship network $(\mathrm{p} \leq .001)$. The average adolescent with $100 \%$ racial difference in friendship networks has mental health scores 2.4 units lower than an adolescent with $0 \%$ racial difference in their friendship network (See Appendix B, Table 22). Model 1 thus provides initial support for the solidarity hypothesis (hypothesis 1a), as more racially homogenous friendship networks are associated with better self-assessments of mental health.

In Model 2, demographic controls are added. Controlling for race and gender partly explains the association between mental health and racial difference in friendship networks. Adolescent's mental health decreases by 0.009 units for every 1 percent increase in racial difference in friendship networks ( $>$ >.05). However, the relationship was no longer significant. Demographic characteristics mediate the association in model 2 , but the returning significance of the racial difference variable in later models suggests that the relationship is not merely a reflection of demographic differences in mental health. Demographic variables were significant, pointing to potential variations in the relationship between race, mental health, and race of friends. Adolescents identifying as any of the racial or ethnic minority categories available all had statistically significant lower scores on the mental health self-assessment in comparison to white adolescents. As 
reflected by the t-tests in Table 2, Asians had the lowest scores, reporting mental health scores 2.615 units lower than white adolescents, the reference group $(\mathrm{p} \leq .001)$. Female respondents also had significantly lower scores than male respondents $\operatorname{did}(\mathrm{p} \leq .001)$.

Model 3 adds controls shown to be significant indicators of mental well-being in the available body of literature. As expected, these nearly all the controls were significant. Friendship quality, a variable that was added out of empirical interest in response to work on differences between "strong-tied" and "weak-tied" friendships, was the exception (Kivijarvi 2015; Knifsend 2013). In Model 3, racial difference of friendship networks regained its significance as an indicator of mental health scores. Model 3 reports that for every one percent increase in the racial difference of friendship network, reported mental health scores decrease by 0.011 units $(\mathrm{p} \leq .05)$.

Furthermore, adding these controls leads to some changes in the demographic characteristic variables. The significant relationship between mental health and two demographic variables_-biological sex and the "other" race category_-is apparently explained by the added controls. On the other hand, the black variable has significant association with mental health scores, with black respondents reporting scores 1.431 units lower than white respondents $(\mathrm{p} \leq .001)$. The negative coefficient for black respondents is strengthened by $85 \%$ from -0.766 to -1.431 . When isolated from other controls in an earlier model, the prejudice variable seems to be most responsible for the change in the black coefficient. The racial difference and black variables increase in prediction power when the prejudice variable is added to the model, which could be an indicator of a minor suppression effect (Thompson and Levine 1997). Nonetheless, this change is small and inconclusive. 
Model 4 tests the hypothesis that racial difference in friendship networks will have a variant impact on mental health self-assessment scores depending on the race of the participant. Model 4 shows support this hypothesis. Only the interaction term between Asian identification and racial difference in friendship is significant. The negative coefficient for Asian adolescents undergoes a 182\% decrease, from -2.194 in model 3 to 6.197 in model $4(\mathrm{p} \leq .001)$. To interpret, Asian respondents with 0 friends of a difference race report mental health scores 6.17 units lower than white respondents with 0 friends of a different race, the reference group. On the other hand, Asian respondents with only friends of a different race report mental health scores 10.17 units higher than white respondents with 0 friends of a different race, controlling for all other variables (See Appendix B, Table 22).

Accounting for the moderators shows that although only the Asian moderator is significant, the relationship between racial difference in friendship networks and mental health self-assessment scores is positive for Asian, Other, and Black respondents. Recall that in table 2, all the non-white adolescents had significantly higher averages of racial difference in friend groups. Asian respondents reported an average score of $40 \%$ racial difference in friendship networks, significantly higher than the average of the full sample $(\mathrm{p} \leq 0.001)$. 


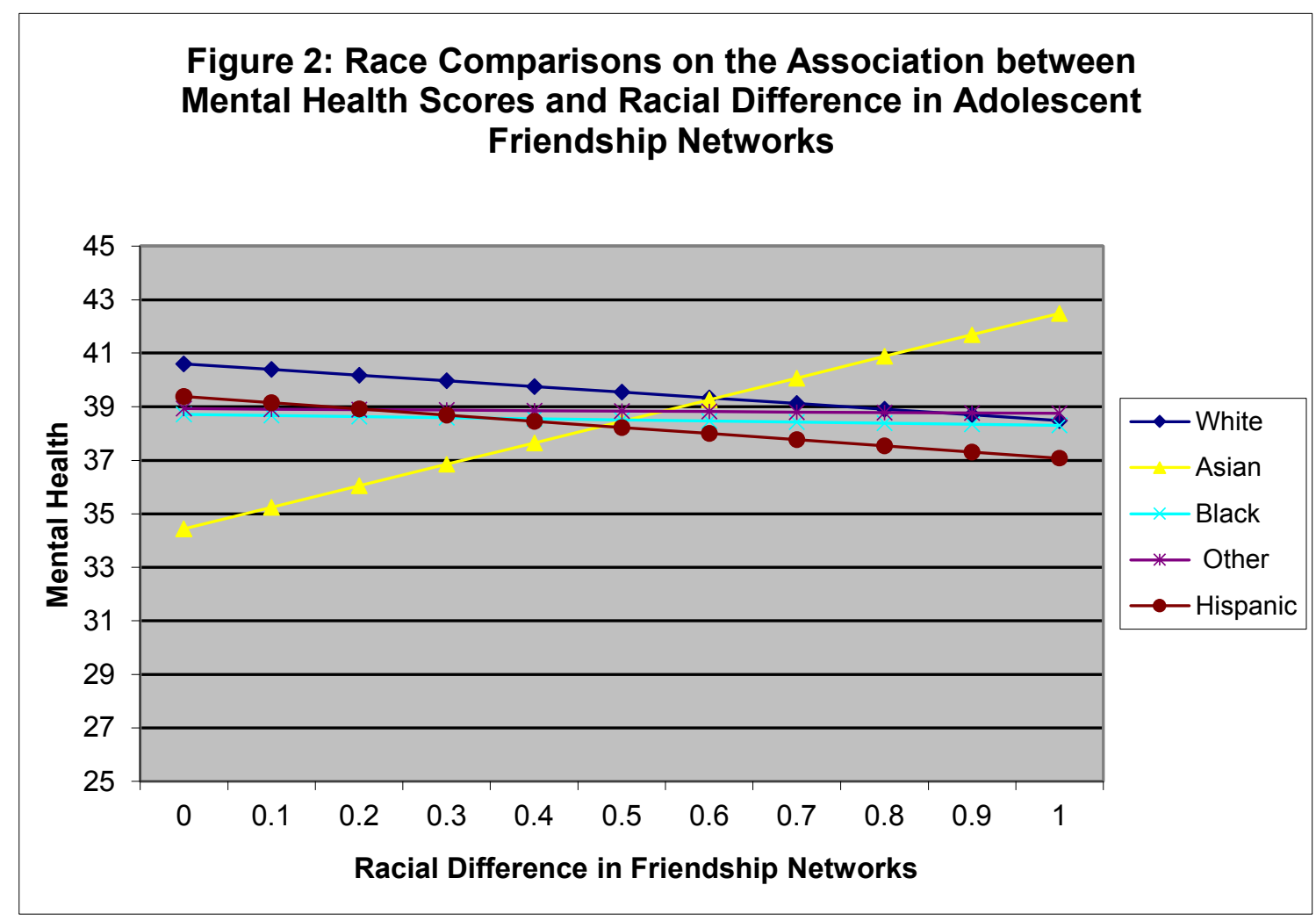

Figure 2 compares the linear regression lines predicting mental health for each racial/ethnic group included in Table 3, Model 4. The regression lines for white, black, other, and Hispanic respondents all show negative associations, with steeper declines for white and Hispanic adolescents. The linear regression line for Asian adolescents is the only one showing a positive association, and Asians with high percentages of racial difference in their friendship networks report better mental health than white adolescents with 0 racial difference in their friendship networks. The interaction variables for black and other respondents are positive but do not significantly change the regression line in comparison to that of the reference group, white adolescents. White and Hispanic adolescents have a downward mental health trajectory as racial difference in friendship networks increases, although the interaction variable for Hispanics was not significant. 
White adolescents have significantly lower racial difference in friendship networks than the rest of the sample, with an average of only $23 \%(\mathrm{p} \leq 0.05)$. With regards to the four racial identities, then, those that report higher levels of racial difference in friendship networks have less negative associations between racial difference and mental well-being, but this relationship is only significant for Asian respondents.

Hispanics represent an exception to this, as they report having friendship networks with an average of $45 \%$ racial difference. However, the fact that it is an ethnicity variable makes things less clear. Because Hispanic is an ethnic category, the "racial difference" percentage does not represent non-Hispanic friends. Rather, it is associated with whatever racial category they identify as. In other words, White Hispanics could be driving the downward trend in addition to White Non-Hispanics, creating the negative association between racial difference in friendship networks and mental health in my linear regression models. In any case, model 4 supports the hypothesis that racial difference in friendship networks varies in its importance for mental health outcomes. Although Model 4 shows, net of controls, that mental health self-assessment scores decrease by 0.021 units for a one percent increase in racial difference, the significance of the Asian X racial difference moderator shows that the relationship is not consistent across racial lines. An adolescent with only friends of a different race would score 2.11 units lower on the mental health scale than an adolescent with only friends of the same race would (See Appendix B, Table 22).

Because there is a large variety of ranges of the variables within the model, standardized coefficients for model 5 are included in Appendix B, Table 13. The "relationship with parent" control variable has the largest standardized coefficient. This 
does not negate the importance of friendships and race of friends in the stress process, but rather points to relationships with parents being a larger than expected contributor to the mental well-being of adolescents.

Table 4 provides supplemental linear regression models predicting the mental health scores of Asian respondents by restricting the sample to include only those identifying as Asian. These models confirm that among Asian respondents, racial difference within a friendship network is positively associated with mental health scores, here measured as lower levels of depressive symptoms. Model 3 shows, net of controls, for every one percent increase in racial difference within an adolescent friendship network, an Asian adolescents mental health score increases by 0.068 units $(\mathrm{p} \leq .05)$. Asian adolescents with $0 \%$ racial difference report mental health scores 6.8 units lower than Asian adolescents with $100 \%$ racial difference do. This is in contrast to the overall negative association between racial difference and mental health shown in Table 3 .

Table 5 is a single-race linear regression model predicting the mental health of white adolescents, the reference category. Supplemental single-race models were also run for black, Hispanic, and other respondents, but did not show any significant associations between racial difference in friendship networks and mental health (Appendix B, Tables 15-20). The supplemental analyses suggest that the negative relationship between racial difference and mental health is primarily driven by the white adolescents within the sample. Only white adolescents showed a significant negative association between the two key variables. Model 3 shows, net of controls, that for a one percent increase in racial difference within white adolescent friendship networks, white adolescent mental health scores decreased by 0.021 units ( $\mathrm{p} \leq .001)$. White adolescents with $0 \%$ racial difference 
thus reported mental health scores approximately 2.1 units higher than white adolescents with $100 \%$ racial difference.

Table 4: Linear Unstandardized Coefficients from Linear Regression Models

\author{
Predicting Asian Adolescent Mental Health
}

Dependent Variable: CES-D

\begin{tabular}{|c|c|c|c|}
\hline & $\begin{array}{l}\text { Model } 1 \\
\text { B }\end{array}$ & $\begin{array}{l}\text { Model } 2 \\
\text { B }\end{array}$ & $\begin{array}{l}\text { Model } 3 \\
\text { B }\end{array}$ \\
\hline (constant) & $\begin{array}{l}33.467 \\
(1.351)\end{array}$ & $\begin{array}{l}35.277 \\
(1.599)\end{array}$ & $\begin{array}{l}22.749 \\
(3.478)\end{array}$ \\
\hline Racial Difference & $\begin{array}{l}0.092^{* *} \\
(0.030)\end{array}$ & $\begin{array}{r}0.078^{*} \\
(0.030)\end{array}$ & $\begin{array}{c}0.068^{*} \\
(0.028)\end{array}$ \\
\hline Biological Sex & & $\begin{array}{l}-2.505^{*} \\
(1.213)\end{array}$ & $\begin{array}{l}-1.153 \\
(1.116)\end{array}$ \\
\hline Relationship with Parents & & & $\begin{array}{l}3.491^{* * *} \\
(0.689)\end{array}$ \\
\hline General Health & & & $\begin{array}{l}1.290^{*} \\
(0.635)\end{array}$ \\
\hline Hobbies & & & $\begin{array}{c}0.502 \\
(0.554)\end{array}$ \\
\hline Friendship Quality & & & $\begin{array}{l}-2.055 \\
(1.943)\end{array}$ \\
\hline Students are Prejudiced & & & $\begin{array}{l}-0.699 \\
(0.502)\end{array}$ \\
\hline $\begin{array}{l}\text { Adjusted R-Squared } \\
n=170^{*}(p \leq 0.05),{ }^{* *}(p \leq 0.01),\end{array}$ & $\begin{array}{c}0.047 \\
{ }^{* * *}(p \leq 0.00\end{array}$ & 1) 0.066 & 0.248 \\
\hline
\end{tabular}


Table 5: Linear Unstandardized Coefficients from Linear Regression Models

\section{Predicting White Adolescent Mental Health}

Dependent Variable: CES-D

$\begin{array}{lcll} & \text { Model 1 } & \text { Model 2 } & \text { Model 3 } \\ \text { (constant) } & \text { B } & \text { B } & \text { B } \\ \text { Racial Difference } & 40.504 & 41.217 & 29.730 \\ & (0.200) & (0.240) & (0.794) \\ \text { Biological Sex } & -0.021^{* * *} & -0.021^{* * *} & -0.021^{* * *} \\ & (0.006) & (0.006) & (0.006) \\ \text { Relationship with Parents } & & -1.413^{* * *} & -0.580^{*} \\ & & (0.268) & (0.250) \\ \text { General Health } & & & 2.142^{* * *} \\ \text { Hobbies } & & & (0.158) \\ & & & 1.995^{* * *} \\ \text { Friendship Quality } & & & (0.144) \\ \text { Adjusted R-Squared } & & & 0.502^{* * *} \\ \text { Students are Prejudiced } & & & (0.115) \\ & & & 0.119 \\ & & & (0.415) \\ & & & -0.791^{* * *} \\ & & & (0.104) \\ & & & 0.186 \\ & & & \end{array}$

Racial Difference in Friendship Networks and Self-Esteem

Linear regression models predicting adolescent's self-esteem are documented in

Table 6. Self-esteem acts as the second half of my analysis of mental well-being. If a relationship between an independent variable and the self-esteem dependent variable is positive and significant, then that variable predicts higher levels of self-esteem among adolescents. Based on my findings measuring the level of depression in adolescents, I 
expect racial difference within a friendship network to be negatively associated with selfesteem assessments. The self-esteem regressions further test hypothesis 1a. Standardized coefficients for the full model (model 4) are included in Appendix B, Table 14.

Contrary to expectations, racial difference within a friendship network is not significantly associated with adolescent self-esteem. Table 6 , model 1 , shows the baseline relationship between racial difference and self-esteem without controls. An adolescent's self-esteem decreased by 0.004 units for a one percent increase in the racial difference of their friendship network. An adolescent with 100\% racial difference in their friendship network would thus report self-esteem scores just 0.40 units lower than adolescents with $0 \%$ racial difference in their friendship network. This finding was not significant $(\mathrm{p}>.05)$. Therefore, hypothesis 1a only has mixed support. Although racial difference in friendship networks is a significant predictor of mental health (measured through reported depression symptoms), it is not a significant predictor of self-esteem. Model 1 provides support for neither the friendships of solidarity (hypothesis 1a) nor friendships of difference (hypothesis 1b) hypotheses.

Model 2 adds demographic controls to the linear regression. The relationship between racial difference in friendship networks and self-esteem remains non-significant, showing only a 0.002 unit decrease for every one percent increase in racial difference $(\mathrm{p}>.05)$. Some of the race and gender variables, however, are significant predictors of self-esteem in this model. African American adolescent self-esteem scores were 0.963 units higher than white adolescents, the reference category ( $\mathrm{p} \leq .001)$. Mirroring the results of the linear regression models predicting mental health, Asian adolescents reported selfesteem scores 1.251 units lower than the scores of white adolescents ( $\mathrm{p} \leq .001)$. Biological 
sex was also a significant indicator of self-esteem, with women reporting scores 1.110 units lower than men did ( $\mathrm{p} \leq .001)$.

Model 3 adds controls shown to be significant indicators of mental well-being in other studies. All the added control variables were significant indicators of self-esteem, including the variable for quality friendship. The quality friendship variable, which was added out of theoretical interest based on studies of the differences between "strong ties" and "weak ties," was only significant in this model—not in the models predicting mental health $(\mathrm{p} \leq .001)$. The demographic variables remain significant. Examining the association net of controls weakens the negative relationship between Asian identification and self-esteem by $37 \%$, from -1.251 in model 2 to -0.785 in model 3 . The coefficient for biological sex is reduced by $41 \%$, from -1.110 in model 2 to -0.647 in model 3 . These reductions suggest that the lower self-esteem among Asians and females is at least partly explained by differences in key indicators of mental well-being.

Perceived prejudice of students was also significant in models 3 and 4, but the coefficient is small ( $\mathrm{p} \leq .05$ in model $3, \mathrm{p} \leq .001$ in model 4$)$. For every one unit increase in perceived prejudice, self-esteem scores decrease by just 0.151 units. Earlier models that added the prejudice variable to the model separate from other controls show that, unlike with the models of mental health, perceived prejudice is not responsible for any large changes in the coefficients for demographic characteristic variables. 
Table 6: Linear Unstandardized Coefficients from Linear Regression Models

Dependent Variable: Modified

Predicting Adolescent Self-Esteem

Rosenburg Self-Esteem Scale

\begin{tabular}{|c|c|c|c|c|}
\hline & $\begin{array}{l}\text { Model } 1 \\
\text { B }\end{array}$ & $\begin{array}{l}\text { Model } 2 \\
\text { B }\end{array}$ & $\begin{array}{l}\text { Model } 3 \\
\text { B }\end{array}$ & $\begin{array}{l}\text { Model } 4 \\
\text { B }\end{array}$ \\
\hline (constant) & $\begin{array}{c}24.947 \\
(0.085)\end{array}$ & $\begin{array}{r}25.330 \\
(0.103)\end{array}$ & $\begin{array}{l}16.891 \\
(0.300)\end{array}$ & $\begin{array}{l}16.859 \\
(0.304)\end{array}$ \\
\hline Racial Difference & $\begin{array}{l}-0.004 \\
(0.002)\end{array}$ & $\begin{array}{l}-0.002 \\
(0.003)\end{array}$ & $\begin{array}{l}-0.003 \\
(0.002)\end{array}$ & $\begin{array}{l}-0.002 \\
(0.003)\end{array}$ \\
\hline Black & & $\begin{array}{l}0.963^{* * *} \\
(0.124)\end{array}$ & $\begin{array}{l}0.842^{\star * *} \\
(0.111)\end{array}$ & $\begin{array}{l}0.977^{* * *} \\
(0.174)\end{array}$ \\
\hline Asian & & $\begin{array}{l}-1.251^{\star * *} \\
(0.271)\end{array}$ & $\begin{array}{l}-0.785^{* * *} \\
(0.235)\end{array}$ & $\begin{array}{l}-2.246^{\star * *} \\
(0.513)\end{array}$ \\
\hline Other & & $\begin{array}{l}-0.312 \\
(0.227)\end{array}$ & $\begin{array}{c}0.011 \\
(0.196)\end{array}$ & $\begin{array}{l}-0.027 \\
(0.389)\end{array}$ \\
\hline Hispanic Origin & & $\begin{array}{l}-0.186 \\
(0.227)\end{array}$ & $\begin{array}{c}0.018 \\
(0.197)\end{array}$ & $\begin{array}{c}0.275 \\
(0.445)\end{array}$ \\
\hline Biological Sex & & $\begin{array}{l}-1.110^{* * *} \\
(0.107)\end{array}$ & $\begin{array}{l}-0.647^{* * *} \\
(0.095)\end{array}$ & $\begin{array}{l}-0.636 * * * \\
(0.095)\end{array}$ \\
\hline Relationship with Parents & & & $\begin{array}{l}1.636^{* * *} \\
(0.057)\end{array}$ & $\begin{array}{l}1.636^{* * *} \\
(0.057)\end{array}$ \\
\hline General Health & & & $\begin{array}{l}0.977^{* * *} \\
(0.053)\end{array}$ & $\begin{array}{l}0.980^{* * *} \\
(0.053)\end{array}$ \\
\hline Hobbies & & & $\begin{array}{l}0.112^{* *} \\
(0.044)\end{array}$ & $\begin{array}{l}0.111^{* *} \\
(0.044)\end{array}$ \\
\hline Friendship Quality & & & $\begin{array}{l}0.674^{* * *} \\
(0.157)\end{array}$ & $\begin{array}{l}0.683^{* * *} \\
(0.157)\end{array}$ \\
\hline Students are Prejudiced & & & $\begin{array}{l}-0.153^{* *} \\
(0.039)\end{array}$ & $\begin{array}{l}-0.151^{\text {** }} \\
(0.039)\end{array}$ \\
\hline Black*Racial Difference & & & & $\begin{array}{l}-0.005 \\
(0.005)\end{array}$ \\
\hline Asian*Racial Difference & & & & $\begin{array}{l}0.036^{* *} \\
(0.012)\end{array}$ \\
\hline Other*Racial Difference & & & & $\begin{array}{c}0.001 \\
(0.009)\end{array}$ \\
\hline Hispanic Origin*Racial Difference & & & & $\begin{array}{l}-0.006 \\
(0.010)\end{array}$ \\
\hline $\begin{array}{l}\text { Adjusted R-Squared } \\
\mathrm{n}=4114 *(\mathrm{p} \leq 0.05),{ }^{* *}(\mathrm{p} \leq 0.01),{ }^{* *}(\mathrm{p} \leq 0.001)\end{array}$ & 0.000 & 0.047 & 0.290 & 0.292 \\
\hline
\end{tabular}


Model 4 tests hypothesis 2, which tests to see if there is racial variation in the impact of racial difference in friendship networks on adolescent self-esteem. Although the direct association between racial difference and self-esteem is not significant, interaction variables still reveal if racial difference in friendship networks might only matter for specific race or ethnic groups. After adding interaction variables, the association between racial difference and self-esteem remains non-significant, showing only a 0.002 unit decrease in self-esteem for every 1 percent increase in racial difference ( $>$.005). The interaction term between Asian identification and racial difference is the only significant moderating variable ( $\mathrm{p} \leq .001)$. The coefficient for Asian adolescents grew by about $200 \%$-from -0.785 in model 3 to -2.246 in model 4 ( $p \leq .001)$. This growth occurs because adding interaction variables changes who is represented by the Asian variable. Asian respondents with 0 friends of a different race report self-esteem scores 2.246 units lower than white respondents with 0 friends of a different race. Meanwhile, Asian respondents with only friends of a different race, the group represented by the interaction variable, are predicted to report self-esteem scores 3.616 units higher than white respondents with 0 friends of a different race (See Appendix B, Table 23)

Figure 3 provides linear representations of the interactions between race and racial difference in friendship networks and their impact on self-esteem in Table 6, Model 4. Although Asian respondents with few friends of a different race have lower selfesteem levels than other race and ethnic groups do, Asian respondents with highly diverse friendship networks have comparable—if not better—self-esteem outcomes.

In conclusion, the racial difference of friendship networks does not have a uniform influence on self-esteem, as Asians appear to benefit from a racially different 
friendship network while the self-esteem of other race and ethnic groups is not as strongly affected. Asians appear to be uniquely influenced by racial difference for not only self-esteem but also mental health, as was shown in earlier analyses.

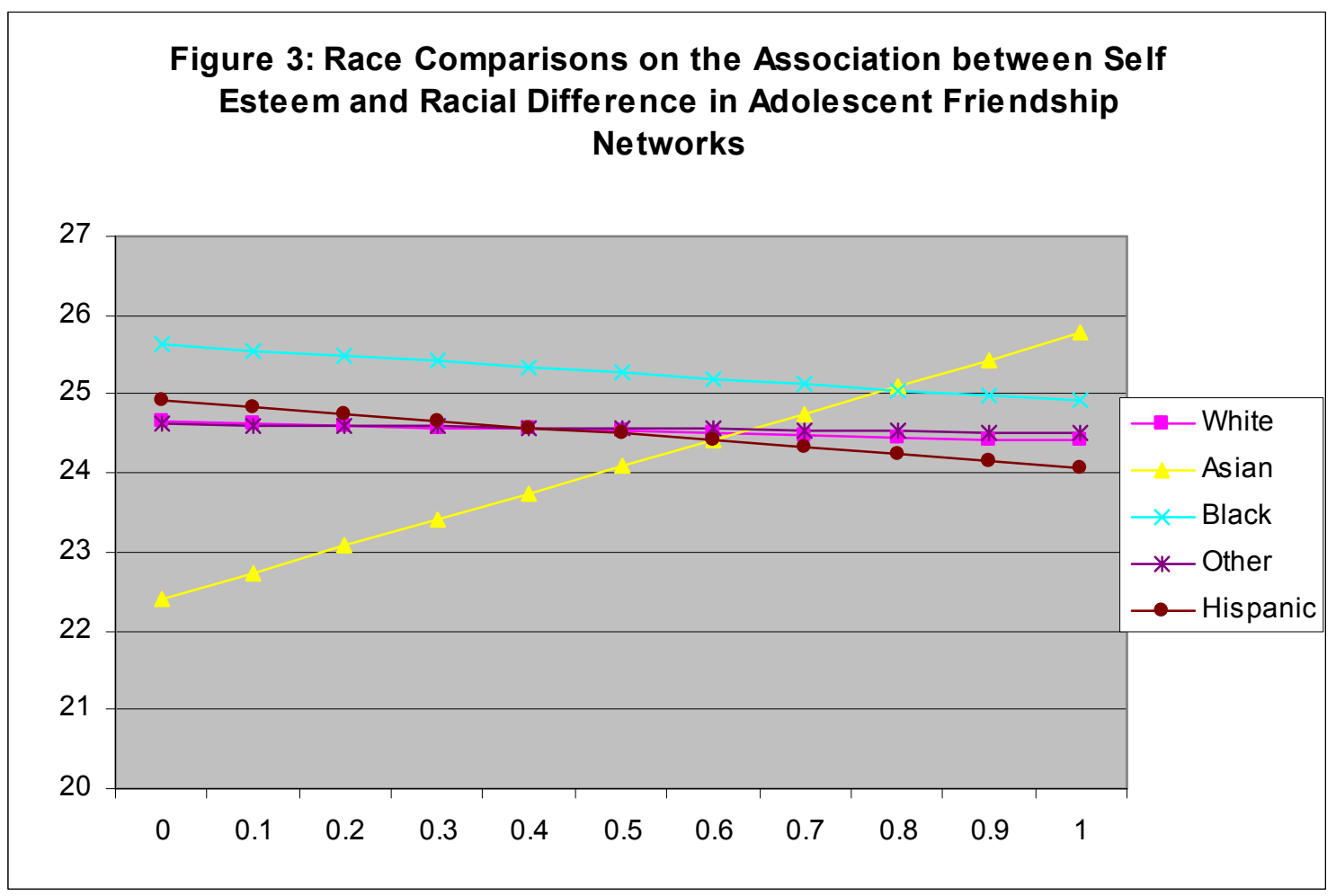


Table 7: Linear Unstandardized Coefficients from Linear Regression Models Predicting Asian Adolescent Self-Esteem

Dependent Variable: Modified Rosenburg Self-Esteem Scale

\begin{tabular}{|c|c|c|c|}
\hline & $\begin{array}{l}\text { Model } 1 \\
\text { B }\end{array}$ & $\begin{array}{l}\text { Model } 2 \\
\text { B }\end{array}$ & $\begin{array}{l}\text { Model } 3 \\
\text { B }\end{array}$ \\
\hline (constant) & $\begin{array}{l}21.791 \\
(0.653)\end{array}$ & $\begin{array}{l}23.171 \\
(0.751)\end{array}$ & $\begin{array}{l}12.867 \\
(1.492)\end{array}$ \\
\hline Racial Difference & $\begin{array}{l}0.041^{* *} \\
(0.014)\end{array}$ & $\begin{array}{c}0.031^{*} \\
(0.014)\end{array}$ & $\begin{array}{l}0.031^{* *} \\
(0.012)\end{array}$ \\
\hline Biological Sex & & $\begin{array}{l}-1.964^{* *} \\
(0.574)\end{array}$ & $\begin{array}{l}-1.355^{\star *} \\
(0.481)\end{array}$ \\
\hline Relationship with Parents & & & $\begin{array}{l}2.409^{* * *} \\
(0.295)\end{array}$ \\
\hline General Health & & & $\begin{array}{l}0.759^{* *} \\
(0.274)\end{array}$ \\
\hline Hobbies & & & $\begin{array}{l}-0.089 \\
(0.239)\end{array}$ \\
\hline Friendship Quality & & & $\begin{array}{c}0.948 \\
(0.840)\end{array}$ \\
\hline Students are Prejudiced & & & $\begin{array}{c}0.103 \\
(0.216)\end{array}$ \\
\hline $\begin{array}{l}\text { R-Squared } \\
\mathrm{n}=172 *(\mathrm{p} \leq 0.05),{ }^{* *}(\mathrm{p} \leq 0.0\end{array}$ & $\begin{array}{c}0.040 \\
1),{ }^{* * *}(p \leq 0\end{array}$ & $\begin{array}{l}0.097 \\
0.001)\end{array}$ & 0.398 \\
\hline
\end{tabular}

Table 7 provides a supplemental analysis of Asian respondents by examining coefficients for linear regression models predicting the self-esteem of Asian adolescents. This supplemental analysis confirms that there is a positive association between racial difference in friendship networks and self-esteem scores for Asian respondents. Model 3 shows that for a one percent increase in racial difference in an Asian adolescent's friendship network, self-esteem scores increase by 0.031 units 3.09 units ( $p \leq .01)$. Asian 
adolescents with $100 \%$ racial difference in friendship networks are predicted to report self-esteem scores 3.1 units higher than Asian adolescents with $0 \%$ racial difference in friendship networks. This confirms that, among Asian adolescents, racially different friendship networks are associated with higher well-being, something that contrasts with other race and ethnic groups (See Appendix B, Tables 15-20 for supplemental analysis of black, Hispanic, and "other race" adolescents).

Table 8: Linear Unstandardized Coefficients from Linear Regression Models Predicting White Adolescent Self-Esteem

Dependent Variable: Modified Rosenburg Self-Esteem Scale

\begin{tabular}{|c|c|c|c|}
\hline & \multicolumn{2}{|c|}{ Model 1 Model 2} & \multirow{2}{*}{$\begin{array}{l}\text { Model } 3 \\
\text { B }\end{array}$} \\
\hline & B & B & \\
\hline \multirow[t]{2}{*}{ (constant) } & 24.784 & 25.398 & 16.377 \\
\hline & $(0.099)$ & $(0.118)$ & $(0.367)$ \\
\hline \multirow[t]{2}{*}{ Racial Difference } & -0.004 & -0.003 & -0.002 \\
\hline & $(0.003)$ & $(0.003)$ & $(0.003)$ \\
\hline \multirow[t]{2}{*}{ Biological Sex } & & $-1.217^{\star * *}$ & -0.802 \\
\hline & & $(0.132)$ & $(0.115)$ \\
\hline \multirow[t]{2}{*}{ Relationship with Parents } & & & $1.755^{\star * *}$ \\
\hline & & & $(0.073)$ \\
\hline \multirow[t]{2}{*}{ General Health } & & & $1.007^{\star * *}$ \\
\hline & & & $(0.066)$ \\
\hline \multirow[t]{2}{*}{ Hobbies } & & & $0.118^{*}$ \\
\hline & & & $(0.053)$ \\
\hline \multirow[t]{2}{*}{ Friendship Quality } & & & $0.663^{* * *}$ \\
\hline & & & $(0.192)$ \\
\hline \multirow[t]{2}{*}{ Students are Prejudiced } & & & $-0.121^{*}$ \\
\hline & & & $(0.048)$ \\
\hline Adjusted R-Squared & 0.000 & 0.030 & 0.292 \\
\hline $\mathrm{n}=2741^{*}(\mathrm{p} \leq 0.05),{ }^{* *}(\mathrm{p} \leq 0.01$ & $\leq 0.001)$ & & \\
\hline
\end{tabular}


Table 8 shows linear unstandardized coefficients predicting self-esteem among white adolescents. Unlike the models examining mental health in earlier analyses, the single-race model of white self-esteem did not show a significant association between the key variables (racial difference and self esteem). Model 3 shows, net of controls, that for a one percent increase in racial difference within a white adolescent friendship network, a white adolescent self-esteem scores decreased by 0.002 units ( $p>05)$. This means that white adolescents with $0 \%$ racial difference report self-esteem scores just 0.2 units higher than white adolescents with $100 \%$ racial difference do. This difference is neither substantive nor significant.

The results of the linear regression models do not support hypothesis 1a or hypothesis $1 \mathrm{~b}$, as racial difference in friendship networks was not a significant predictor of adolescent self-esteem for any racial/ethnic group other than Asian adolescents. The results of the linear regression models predicting self-esteem do provide some support for hypothesis 2 , which suggested that racial variation on the importance of racial difference in friendship networks would be present. Potential reasons for the uniqueness of Asians with regards to the importance of racial difference and the negative relationship between racial difference and white adolescent mental health are discussed below. 


\section{Chapter 5: Discussion and Conclusion}

Interpretation of Results

The results of the regression analyses predicting mental well being through measures of depressive symptoms and self-esteem provide mixed support for the two hypotheses. Hypothesis 1a stated that racial similarity within an adolescent's friendship network would be associated with mental well-being. This is supported by the significant negative coefficient in the regression models predicting mental health of adolescents. However, supplemental analyses reveal that this result might be primarily affected by the predominantly white sample. In addition, racial difference in friendship networks was not a significant predictor of self-esteem, leading to mixed support for hypothesis 1a.

Hypothesis $1 \mathrm{~b}$, the alternative hypothesis stating that racial difference within an adolescent's friendship network would instead be associated with increased mental wellbeing, also had some support in the models. There was a positive association between racial difference and both mental health and self-esteem for Asian adolescents.

Hypothesis 2, which states that the association will vary significantly by the race and ethnicity of the respondent, is supported. Supplemental analyses found that only white respondents had a significant negative association between the level of racial difference in friendship networks and mental health, and only Asian respondents had a significant positive association between the level of racial difference in friendship networks and mental well-being.

Although black, Hispanic, and "other race" adolescents also had negative associations between racial difference and mental health measures, these associations were non-significant (see Appendix B, Tables 15-20). Similar mixed results show up in 
models of self-esteem. The interaction variables for black and "other race" adolescents were positive in the model predicting mental health, but these coefficients were not significant. Note that in the original models showing interaction variables, each group is assessed with white adolescents serving as a reference category. As such, the positive coefficients on interaction variables suggest that racial minorities are less detrimentally impacted by racially different friends in comparison to white adolescents. Black, Hispanic, and other-identifying adolescents do not show a relationship between racial difference and mental health that is significantly different from white adolescents, and supplemental analyses show that there is a non-significant association between racial difference in friendship networks and mental well-being for these demographic groups. The negative association between the racially different friendship networks and mental well being is thus driven by the large sample of white adolescents in the sample, who are the only group to show a negative association in the single-race supplemental models.

Although there was no significant association between racial difference and selfesteem according to the regression model, the moderator for Asian was significant and positive. Interaction variables reveal that, while racial difference in friendship networks is generally associated with lower mental health, Asians experience a reverse trend in which higher racial difference is associated with better mental health. Breaking down the analysis by creating separate models by race supports that there is indeed a significant positive association between racial difference of friendship networks and both the mental health scale and self-esteem scale for Asian adolescents. These supplemental models support hypothesis 2 by finding that Asian adolescents represent a unique group with 
respect to the relationship between racial difference and mental well-being, as measured by self-esteem and (less) depression.

In order to fully comprehend what the mixed results of my study might mean, I will first break down what the results of my study add to the available literature on the stress process and contact theory. Then, I attempt to synthesize these two theories in light

of my results for the purpose of future analyses. Next, I will attempt to explain why Asian adolescents and White adolescents represent unique groups within the analysis. After providing this explanation, I will discuss potential policy implications, limitations of the research, and areas for future research.

\section{Theoretical Contributions: The Stress Process}

Part of my motivation for this study was to point out how social characteristics like race and gender that are often seen as indicators for exposure to unique stressors or specific outcomes also influence the role that mediating buffer resources play within the stress process. In the case of social support, the resource itself has social characteristics attached to it. Interracial and interethnic friendships are not only less common but may be less socially accepted than same-race friendships (Pettigrew 1998; Kivijarvi 2015; Miller and Kail 2016). Additionally, same-race and different-race friends may serve different functions and thus play a role in combating different types of stressors. In this study, I focused on determining if racial difference in friendship networks had a main effect on the mental well-being of adolescents, using depressive symptomology and self-esteem to measure it. Although I cannot claim causality, the main association between racial difference in friendship networks and mental well-being varied by the group in question. This variation is a key finding that points to the fact that social support is not a stagnant 
resource, but rather something that changes based on who is providing the support and who is receiving it.

The variation by race of respondent is not extremely surprising, as other studies have found that certain demographic groups rely on different sources of social support (Pearlin 1999; Burke 2015; Corona et al 2017; Harven 2014; Kao and Joyner 2004; Mossakowski and Zhang 2014). For example, Asian immigrant children often seek out different-race friends in order to find a sense of belonging within American society (Tummala-Nara and Sathasivam-Ruekert 2016). The positive relationship between racial difference in friendship networks and mental well-being for Asian adolescents supports this line of research. In fact, Asian adolescents_ not just Asian immigrant adolescentsmight seek out racially different friends more often than other groups. On the other hand, they may also be more accepted by other racial/ethnic groups in comparison to other minorities. One other commonly found variation is that Hispanic people tend to rely more on familial social support (Corona et al 2017; Harven 2014). My study found that better relationships with parents were actually associated with better mental well-being for all race/ethnic groups within the sample, not just Hispanic adolescents. As such, the strength of the relationship with parents variable warrants its inclusion as a control in future studies of adolescent mental health, regardless of the racial/ethnic identification of the group being studied.

Meanwhile, there was no significant relationship between racial difference in friendship networks and the either of the dependent variables for Hispanic, Black, or "other race" respondents. Of course, friendship likely still plays an important lives in the role of all adolescents. The race of one's friends, too, is not confirmed to be non-existent 
by the results of this analysis. Rather, the non-significant results could just be the result of insufficient data and random error. Future studies should also check the "buffering" effects of race of friends, as this is the other integral piece of the study of mental health resources in the stress process. The current study explored only main effects, as it asked whether or not racial difference in friendship networks predicted better mental well-being regardless of the current level of distress being experienced by the respondents. "Buffering" effects are those in which resources like social support are triggered to combat higher levels of psychological distress. In the case of race of friends, perhaps same-race friends rise in importance as a predictor of mental health as respondents experience higher levels of discrimination. On the other hand, different-race friends may be more important as adolescents struggle with the stress of acculturation.

The variation in the role of race of friends also points to the need to look at what other types of stress it might buffer. Stress resulting from prejudice is a measure closely related to stigmatized identities (Thoits and Link 2016). Such prejudice might make relationships with same-race friends important due to the need to discuss one's experiences with someone else who understands them (Harven 2014; Tummala-Nara and Sathasivam-Rueckert 2016; Soto et al 2016). On the other hand, stress resulting from acculturation might make different race friends an important resource, as having them could help minority youth develop a sense of belonging with in-group peers (TummalaNara and Sathasivam-Rueckert 2016; Kivijarvi 2015; Baiocco et al 2014; Knifsend 2013). But stressors like financial stress that are not necessarily "racial" should still be tested now that a main association between race in friendship networks and mental well-being 
has been established. Perhaps, for example, having white friends brings a certain amount of access to monetary resources that other minorities might typically lack knowledge of.

Lastly, the role of social support in the stress process should further be tested by identifying the race of the friends specifically. My measure of racial difference tests only if the friend is of a different race than the respondent. But, given the varying rates by race of depressive symptoms and self-esteem as well as the difference in the impact of race of friends in the models, specific races of friends might have different mental health outcomes attached to them. For example, perhaps friendships that occur between different minority groups have less anxiety than minority-white relationships. Hispanic and Black adolescents might have more similar experiences and thus be able to rely on one another for social support in times of increased prejudice. Having white friends, as mentioned, might provide some access to privilege for minority groups.

\section{Theoretical Contributions: Contact Theory}

Contact Theory states that intergroup contact leads to better racial attitudes, conditional on equal status, common goals, intergroup cooperation, and support from authorities (Allport 1954; Pettigrew 1988). Contact Theory is not directly related to stress or mental health but provides a useful framework for understanding the function of intergroup contact in changing behavior. It is perhaps most connected to mental health through the connection with prejudice, a variable that was a key control within the analysis. Previous studies have shown that stress from perceived prejudice is countered by minority groups through social support from same race friends (Tummala-Nara and Sathasivam-Rueckert 2016; Hughes et al 2014; Noh and Kaspar 2003). A "safe space" of shared experiences allows minority adolescents to cope with prejudice and create stable 
identities that deny these stereotypes (Hill Collins 2000). On the other hand, intergroup contact may play a role in creating better racial attitudes over time but still expose adolescents to prejudicial experiences and racialized stress (Allport 1954; Pettigrew 1998). In this study, white adolescents in particular face declining mental well-being if they have more friends of a different race. Perhaps, then, better racial attitudes also mean more racial awareness, increasing perceptions of prejudice and stress associated with this prejudice.

Tests of racial difference in social support from romantic relationships do show that white women experience heightened stress resulting from exposure to prejudice through the experiences of their partners and a diminished support for their relationships (Miller and Kail 2016; Yancey 2007). Adolescents with different race friends might face a similar disadvantage. Of course, note that the addition of the "experienced prejudice" variable did not make the relationship between racial difference in friendship networks non-significant (Table 3). The relationship is only partly mediated by experienced prejudiced. Explanations for the general trend toward lower mental health among adolescents with a higher proportion of different race friends thus must also consider other types of stress.

This study also contributes to the literature on contact theory because it shows that white adolescents, who report the lowest average racial difference in friendship networks, tend to report lower mental well-being if they have more racially different friends (See Table 2). Asian adolescents had an average of $40 \%$ racial difference in friendship networks within the network and were the only group to have a significant positive relationship between the racial difference variable and both the measures of 
mental well-being (mental health and self-esteem). Black adolescents are near the middle, reporting an average of $30 \%$ on the racial difference network variable. Racial difference in friendship network was not a significant predictor of mental well-being for black adolescents, and the coefficient showed non-significant association. White adolescents reported the lowest average at just $23 \%$. Although white adolescents on average had the highest scores on the mental health scale, supplemental analyses showed that white adolescents were the only group with a significant negative association between the racial difference variable and the mental health scale.

This study thus adds to contact theory by showing that the negative relationship between racial difference and mental well-being is diminished—if not altogether reversed - among groups who have more intergroup friendships. The higher percentage of racially different friends suggests more positive, cumulative intergroup contact. Since such intergroup contact may create some degree of racial anxiety if it is a newer experience, the percentages may be an indicator of comfort with people of different races. As a result, the racially different friends become more capable supportive resources for adolescent youth. Contact Theorists have shown that one barrier to better racial attitudes and intergroup contact is that out-groups are often perceived as threatening, in part due to negative stereotypes such as the labeling of black men as criminals (Pettigrew 1989; Powers and Ellison 1995). Similarly, if minorities have experienced prejudice from white adolescents, they are likely threatened by predominantly white-spaces and less likely to befriend white adolescents (Soto et al 2016). The populations with the lowest racial difference in friendship networks were white adolescents and black adolescents. Perhaps, then, these groups feel more "threatened" by different racial groups, impeding 
the ability of interracial or interethnic friendships to be strong social support resources. This threat could make the presence of such friends more anxiety-inducing, leading to poorer mental health outcomes.

To conclude, then, contact theory adds two potential explanations for the results of this study. Firstly, an individual who has more friends of a different race might experience more stress along with an accompanying change in racial attitudes. Awareness of the experiences of minority friends in particular might increase the stress of adolescents who are more aware of prejudice in their daily lives. Secondly, a racial group that typically has less experiences or interactions with other racial groups might have individuals who experience more anxiety in the interactions with out-group adolescents. This group anxiety might be overcome with time, but perceived threat of different race adolescents likely makes them a less reliable social support resource. If an adolescent feels anxious or threatened by a peer, they are probably less likely to go to them for advice or assistance.

\section{Theoretical Contributions: Synthesizing the Stress Proccess and Contact Theory}

The following section uses knowledge of the two theoretical frameworks discussed and the results of my study in order to create a synthesized stress processcontact theory model that can inform directions for future research. This research project aims to test the value of combining contact theory with the stress process model. It asks if the intergroup contact that is central to contact theory has an impact on how friendships function as a social network resource. This is a starting point for understanding how the two theories work together; however, a full analysis of an integrated stress processcontact theory model requires studying how intergroup contact changes over time. Based 
on the contact theory literature, it is clear that different stressors and mediators arise throughout the process. The increase of positive racial attitudes explained by the contact theory develop over time, as members of one group begin to generalize their positive experiences with minorities to represent the whole group (Pettigrew 1998). At different times in this process, intergroup relationships face different barriers that can create undue stress for individuals.

In order to better visualize this process, I have attempted to combine Pettigrew's model of contact theory (see Appendix B, Figure 5) with Pearlin's stress process. My research project cannot make claims about the validity of this model (Figure 4), as doing so requires longitudinal analysis. Rather, this thesis tests and provides support for the core proposition on which the model rests - that intergroup contact in the form of racial difference in friendship networks leads to different mental well-being outcomes. 


\section{Figure 4: Sythesized Model of the Stress Process and Contact Theory}

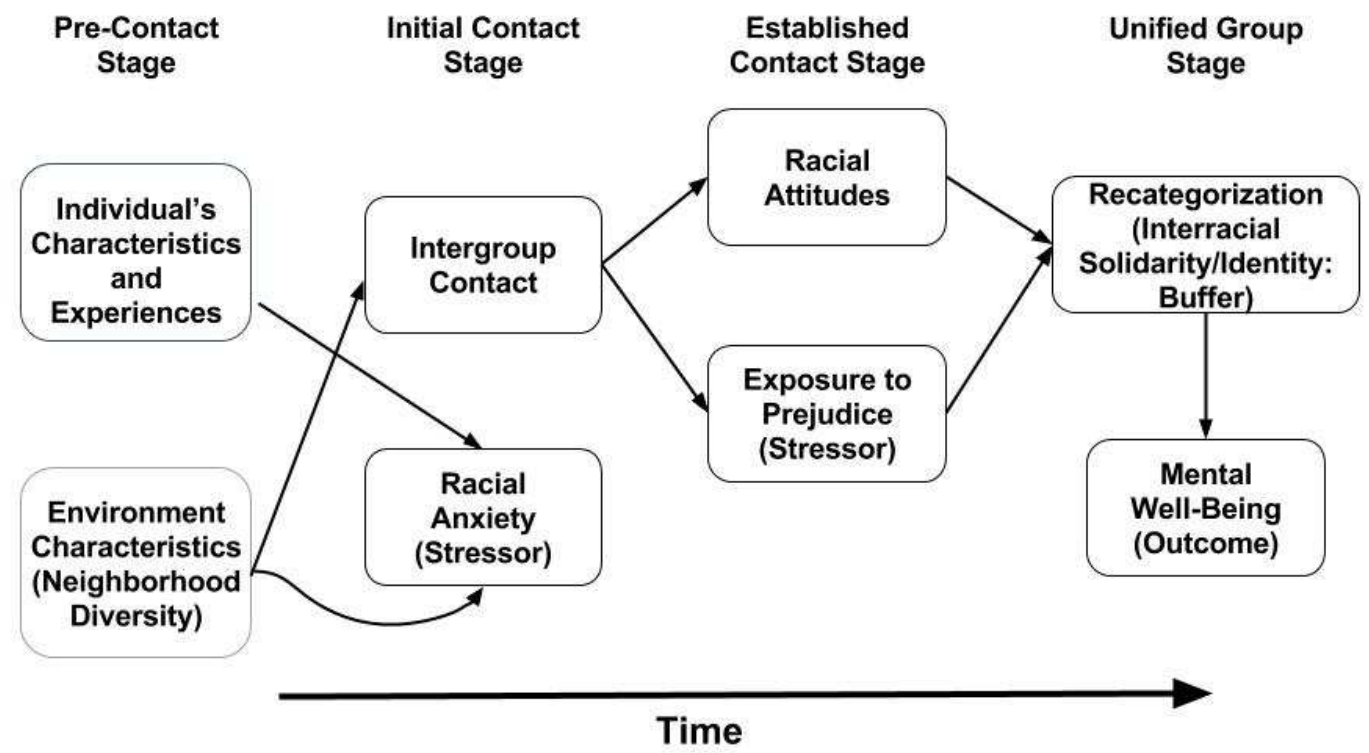

In the pre-contact stage, characteristics of both the individual and the environment surrounding them determine how difficult it is to establish the four conditions of contact theory and the level of stress when contact is first established. Individual characteristics include racial attitudes before the contact experience, as extremely poor attitudes might lead to beliefs that the individual is of greater status than out group members.

Environment characteristics impact the reception of intergroup contact because it helps determine both previous exposure and how others might perceive the contact. If racial attitudes are poor among a family, for example, then contact with out-group members might fail to meet the condition that the contact is supported by authorities. 
These characteristics also predict the level of racial anxiety experienced in the initial contact stage, which is one of the key instances in which the stress process and contact theory overlap. Individuals who have little to no knowledge of out-group members will likely be more fearful when exposed to this unfamiliar contact. Similarly, studies have shown that people living in desegregated neighborhoods tend to develop more positive attitudes about other racial groups over time (Pettigrew 1998). Those living in segregated neighborhoods often fear being ostracized by "in-group" members if they choose to engage in intergroup contact. Studies on the accusation of "acting white" suggest that this extends to minority groups who create relationships with dominantgroup friends (Durkee and Williams 2015). This fear is demonstrated by the significance of the negative relationship between racial difference in friendship networks and mental well-being among white adolescents. These adolescents might experience a diminishing of support from same-race peers, parents, authorities, etc., in response to increases in intergroup contact. Future longitudinal studies should thus check to see if increases in racial difference in friendship networks corresponds to a loss of support from other social network variables.

The results of this study primarily speak to the "established contact" stage within the model. During established contact, cumulative intergroup contact grows into stronger bonds between in-group and out-group members. Such bonds are represented in the data by the levels of racial difference in friendship networks. At this point, individuals engaging in intergroup contact develop enough positive attitudes to treat out-group members as friends. They begin deconstructing negative stereotypes associated with that friend's racial identity. In other words, racial attitudes being to generalize. At the same 
time, however, the adolescent's association with out-group members makes them both more prone to experiences of prejudice and more aware of the effects of prejudice. The racial anxiety stressor likely fades as stronger bonds form but is replace by a second stressor: exposure to prejudice. How this stressor functions likely varies based on if the individual in question is a member of the dominant or marginalized group. For example, a white adolescent experiences stress from prejudice second-hand through the experiences of non-white friends. This is similar to the experience of white women married to minority men (Yancey 2007; Bratter and Eschbach 2006). Studies show that such women cite increased stress associated to a greater awareness of the prejudice of white peers as well as structural inequalities like unfair treatment from law enforcement (Bratter and Eschbach 2006). Minority adolescents similarly face more exposure to prejudice because they come into contact with more dominant group members who are still in the process of changing racial attitudes. Also, positive intergroup contact with one adolescent does not necessarily mean there is more positive contact at the societal level. Intergroup contact with a white friend could, for example, expose a minority adolescent to discrimination from other white adolescents within that friend's peer group who have much poorer racial attitudes. Groups who experience less stereotyping and prejudice, such as the Asian adolescents within my sample, might be more able to find a sense of belonging amond different-race peers frequently and quickly because of lower amounts of stress related to such increases in prejudice. To summarize, the established contact stage within the stress process-contact theory hybrid model shows that increases in positive racial attitudes need not correspond to less stress from prejudice. 
In any case, I speculate that just as positive racial attitudes increase and generalize over time, the stress related to prejudice likely fades as these attitudes improve. Dominant group adolescents like the white adolescents within my sample might begin developing better coping mechanisms and social support networks to combat their increased exposure to prejudice. Similarly, the increases in positive attitudes likely correspond to a greater sense of belonging for minorities among predominantly white spaces.

These changes lead to the "unified group stage." Contact theorists state that very few intergroup contact experiences actually reach this point, but it nonetheless provides a crucial "end point" that explains the progression of racial attitudes within the synthesized models (Pettigrew 1988). "Recategorization" describes the diminishing of identifying an "out-group" person as an "other." As social networks become more integrated, individuals reframe what their own identities mean to them (Pettigrew 1988). Immigrant studies examining the importance of a "Pan-ethnic" identity help illustrate what this might look like (Tummala-Nara and Sathasivam-Rueckert 2016; Goza and Ryabov 2009). Immigrants with a "Pan-Ethnic" identity are able to find a sense of belonging within a dominant culture without abandoning the same-ethnic networks that are not only sources of social support but also parts of the individual's identity. Within the "unified group stage," individual's increase important social network and coping resources that contribute to stronger mental well-being and the ability to combat increased stress. "Racial identity" has been shown to buffer stress among black populations by increasing self-esteem resources (Hughes et al 2014). A similar “interracial identity" might develop for individuals who are able to create strong, positive intergroup networks. Individuals in the unified group stage are theoretically able to establish feelings of solidarity among 
people from different backgrounds. Ideally, this means that friendships of difference become friendships of solidarity, and adolescents are able to gain value from both samerace and different-race friendships.

The findings of this study provide direction for the creation of this model and future work. I propose that future studies aim to test how contact, attitudes, and stress work together to create different mental health outcomes. In the next part of this discussion, I will focus on the empirical aspects of this project and their implications for studies aiming to test this synthesized model.

\section{Why do Whites with racially different friends have lower mental health?}

White adolescents have a negative association between racial difference in friendship networks and mental health, meaning whites with more diverse friend groups reported higher levels of depression. This result should not suggest that whites need to have primarily same-race friends to have stable mental health. Rather, when looking at the available literature in light of these findings, white women seem to face a "burden" in interracial romantic relationships (Miller and Kail 2016; Yancey 2007; Bratter and Eschbach 2006). Although romantic relationships and platonic relationships likely behave differently in many regards, the results suggest that this "burden" might extend in some way to the interracial friendships for both white men and white women. The "burden" in question is that white adolescents with more different race friends might be more exposed to prejudice indirectly by hearing about the treatment of their minority friends or witnessing it first hand. This might create guilt, a sense of responsibility, or a shock that leads white adolescents to experience stress as a result of the experiences their friends face. Research shows that women especially cite social networks as a key source of stress 
because they worry about the lives or conditions their friends and family face more often (Elliot 2013). Future studies should qualitatively identify the experiences white adolescents with more diverse friend groups face that are directly related to their friendships. Such interracial friendships might have a stigma similar to that of interracial romantic relationships. This stigma could come in the form of a lack of support from family for the friendship or an increase in stereotyping or labeling of the white adolescent for associating with "undesirable" youth. Such relationships expose white adolescents to the impact race has, increasing awareness of prejudice in their schools.

Although Contact Theory illustrates how positive intergroup contact leads to better racial attitudes overtime, it also warns that intergroup contact can also at times create a certain racial anxiety when meeting groups that are, for the most part, unfamiliar (Pettigrew 1988). This initial anxiety provides a barrier to the creation of different race friendships. T-tests showed that white adolescents were the demographic group with the lowest average of racial difference in friendship networks. White adolescents may have less exposure to minority groups and thus experience some form of anxiety when meeting people of a different race. Although minorities likely face the same experience, there might be a higher likelihood that they have overcome such racialized anxiety through repeated contact with other racial groups. In order to test this, it is important to consider multi-level school and neighborhood data in the future. The racial diversity of a friendship network is likely influenced by the diversity in school and neighborhood. Since white adolescents make up a large proportion of the available sample $(\mathrm{n}=2735)$, white adolescents are more available for friendship reporting. This makes same-race friends more available for white adolescence than they are for minority youth, who may 
attend schools where they are more outnumbered. Additionally, adolescents - especially those from immigrant minority populations — strive to find a sense of belonging among their peers (Tummala-Nara and Sathasivam-Rueckert 2016) Eric Ericson (1950) identified peers as the most important social group in adolescence because adolescent youth begin to shape and attain their identities as people. Identity formation is done in part through comparison with other peers and finding a "niche" within a school. As such, it is possible that minorities will feel more pressure to attach themselves to different-race peers in comparison to white adolescents, who are more likely to be the majority group within a paired-school network. This means that minorities will have more intergroup contact with different race peers including white adolescents, less racial anxiety because of this increased contact, and an inclination to seek out different-race peers in order to fit in with in-group populations. 
Why are Asian Adolescents unique?

Asian adolescents had a positive association between racial difference in friendship networks and mental health. Additionally, supplemental analyses of selfesteem reveal that despite the overall lack of significance in the relationship between racial difference in friendship networks and self-esteem, Asian adolescents had a significant positive association for the two variables. Previous studies have suggested that Asians rely less on social support and "formal" interventions, especially in attempting to combat the stress that results from prejudice (Mossakawski and Zhang 2014; TummalaNarra and Sathasivam-Rueckert 2015). The results of my study, however, point to the need to understand the type of friend being analyzed within the stress process (type in this case meaning the race of the respondent, but other demographic characteristics or even "niche" group identities could also be studied). In order to fully understand why Asian adolescents are a unique group, literature on immigration status and contact theory should be brought into conversation with one another.

Asia is the second largest birth region for U.S. immigrants, and Asians are the fastest-growing U.S. race group (United States Census 2010). Although I did not control for immigrant status, such a variable might explain the significant difference between Asians and the other racial and ethnic groups studied. Acculturation stress is particularly strong for immigrants, as they must learn how to come to terms with having a culture at home that is significantly different from the culture they experience at school (TummalaNarra and Sathasivam-Rueckert 2015). Such a clash can often lead to increased conflict with parents and a resulting diminishing of perceived social support at home. This is in part because parents tend to acculturate at a much slower pace than do children 
(Tummala-Narra and Sathasivam-Rueckert 2015; Mossakowski and Zhang 2014). In other words, parents are perceived as out of touch with the problems of the adolescent, so the adolescent turns to other forms of informal support when they are struggling. So, they turn to friends who they believe might better understand their experiences. In fact, it has been shown that immigrant children who are most likely to succeed are those who are able to create a pan-ethnic identity in which they both preserve the bonds with their ancestral culture but also find a place within the new society they belong to (TummalaNarra and Sathasivam-Rueckert 2015). Such success is in line with the results of this study when looking at the mental well-being of Asian adolescents.

But only part of the Asian adolescents within the sample are 1st generation immigrants, so other factors must be considered. However, the desire to belong and acculturation stress likely does not completely disappear for racial minorities of later generations. I speculate that the positive relationship between racial difference in friendship networks and mental well-being may have something to do with the small (but nationally representative) sample of Asian respondents (only $4 \%$ of the sample). Firstly, because Add Health data were collected at the school-level, the small population of Asian adolescents suggests that they as a group likely have more contact with other racial/ethnic groups at schools. School level data on racial diversity is needed to confirm this. In this sense, Asians may be more comfortable with different race friends simply because there is a limited supply of same-race friends. Secondly, the research on immigrant status and the stress of acculturation does not close out the possibility that a similar acculturation stress can occur when a population is in a clear minority. In the case of sexual minorities, for example, having heterosexual friends is positive for mental well-being because it 
gives sexual minorities a feeling of being accepted by the larger social world (Baiocco et al 2014). Asian adolescents, regardless of generation, might experience a similar "outnumbered" experience in which establishing strong bonds with racial-majority friends leads to a stronger sense of belonging and acceptance.

In the sample, Asian respondents had one of the highest rates of racial difference within friendship networks, with an average of $40 \%$ non-Asian friends. Asians also constituted just The higher rate of diversity shows a balance between Asian friends and non-Asian friends - both of which play an essential role in mental well-being. Future studies should seek to test if there is a "critical point" or ideal percentage in the relationship between same-race friends and different-race friends. Such a finding would also be in line with literature showing that creating a pan-ethnic identity is essential for Asian adolescents. Asian adolescents might turn to other Asian peers when experiencing discrimination. Having more same-race peers within a friendship network also reduces exposure to discrimination or prejudice, something that seems to occur for all minority youth to some extent (Ueno 2009) On the other hand, having a percentage of differentrace friends allows Asian adolescents to develop a sense of belonging within "mainstream" culture. Cultivating relationships with "in-group" members such as white adolescents might also bring minorities better access to resources they might ordinarily be excluded from. In this way, by creating a diverse network of friends, Asian adolescents are able to both preserve "ethnic cultural capital" through interactions with family and same-race friends and discover a new health advantage through intergroup contact by developing a sense of belonging within a more integrated society. Note that 
racial minorities who have romantic relationships with white men and women encounter a similar health advantage through their partner (Miller and Kail 2016).

Contact Theory states that intergroup contact decreases negative attitudes toward out-groups and replaces such attitudes with respect. It also allows them to lessen stereotypes and prejudices that are often chronic stressors for minority groups. However, contact theory is centrally about racial attitudes--not mental well-being. Unlike the other racial groups tested, supplemental analyses of Asian adolescents showed that there was no significant relationship between perceived prejudice and two measures for mental well-being (mental health and self-esteem). According to T-tests looking at the means of perceived prejudice among the different race/ethnic identities in the sample, Asians adolescents report a lower average of perceived prejudice in comparison to the other groups ( $p \leq .001)$ (See Appendix B, Table 21). Asian adolescents have "ethnic networks" that they can rely on when prejudice is experienced, but might be less off-put or threatened by other minority groups and, in turn, more willing to engage in intergroup contact.

Asians are sometimes viewed as closer in whiteness than other minority groups, a view that is somewhat reflected in "positive stereotyping" of Asians as intelligent. These stereotypes might allow Asians to gain a sense of belonging more quickly in predominantly white spaces. This is not to say that Asian adolescents don't experience discrimination, but rather that the benefits of feeling "belonging" among in-group peers is greater than the threat of experienced prejudice or discrimination. This in turn increases intergroup contact and lowers stereotyping further, allowing Asian adolescents to develop a pan-ethnic identity while other minority groups struggle to combat more pervasive, 
negative stereotypes. To put it another way, contact theory literature shows that, in some cases, the creation of bonds through intergroup contact is obstructed by strong negative stereotypes and images associated with an unfamiliar group (Pettigrew 1988; Soto et al 2016). Asian respondents might be viewed as more "similar" to white majority adolescents, less threatening, or more familiar in comparison to other racial minorities. Black and Hispanic adolescents tend to go to more segregated schools as well, making them a less familiar minority presence to white-majority adolescents (Kao and Joyner 2005; Ueno 2009). Additionally, there could be an important intersection between the race and class of adolescents within the sample. Add Health does have network data on the "class difference" in friendship networks, so future research could check to see if part of the positive relationship between racial difference in friendship networks and mental health is partly explained by class similarity in their friendship networks.

Future studies should reconsider the importance of friendship as a source of social support for Asian adolescents by accounting for the race of friend and exploring the way in which contact and exposure to prejudice interact. Studies should investigate why other groups with diverse friendship networks do not have similar a similar "mental health advantage," and use studies of Asian adolescents to better determine how integration policies can account for the stress that an interaction between two cultures or racial identities might cause.

Why wasn't racial difference significant among Black, Hispanic, or Other Adolescents?

Supplemental analyses show that the significance of the negative relationship between racial difference in friendship networks and mental health was driven primarily by the large proportion of white adolescents within the sample. Unlike the positive 
relationships found among Asian adolescents, Black, Hispanic, and other adolescents all showed slight negative but non-significant relationships between racial difference in friendship networks and the mental well-being measures. Because these results are nonsignificant, I cannot make any conclusions about the relationship between these variables for Black, Hispanic, and "other" race adolescents. As such, this section is largely speculative but discusses potential implications that should be verified in future research.

The non-significant results are perhaps most surprising for black adolescents given the extent to which they represent a unique population in the available literature. Studies have shown that same-race friendships are important in countering experienced prejudice (Harven 2014; Mossakowski and Zhang 2014; Noh and Kaspar 2003; Tummala-Narra and Sathasivam Rueckert 2016). Black adolescents face many pervasive stereotypes, but those with higher proportions of different race friends did not face significant declines in their mental well-being. Research also shows that non-black adolescents report little shared activity with black friends (Kao and Joyner 2004). There are a couple explanations for the surprising non-significance of racial difference for black adolescents.

It is possible that black adolescents only need a certain percentage of same race friends to buffer the stress from discrimination. Best friends tend to be of the same race and would also provide a source of informal support in addition to the support of family. Also, the Add Health sample of black respondents actually reported lower levels of perceived prejudice, but this was non-significant and not specific to personally experienced racial prejudice (Appendix B, Table 21). The unexpected, small suppression effect that occurred when perceived prejudice was added to the models predicting mental 
health could be related to the low perceived prejudice reporting among black respondents. Firstly, because the measure is general and not specific to race, the low mean could point to lower perceptions of other types of prejudice. Secondly, black adolescents may perceive less prejudice because of school related variables such as the level of racial diversity at their schools. If the school they attend is primarily black, they are probably less likely to view their peers as prejudiced against them because of their race. In any case, future studies should focus more centrally on the relationship that prejudice has with racial difference in friendship networks.

Immigrant status could play a key role for some respondents, as immigrant black populations might have more of a need for different race friends than do native black populations. Separating black adolescents into two distinct group based on immigration status might reveal similar results to the positive association between racial difference in friendship networks and mental well-being among Asians. Nonetheless, I expect the immigrant black population to be small in the sample.

Another possibility for the null finding is that the potential "health advantage" from having friends from racially privileged background could disguise the potential disadvantage from increased experiences of prejudice through negative intergroup contact. In other words, white friends might be a less equipped resource for buffering stress that results from acculturation or prejudice but more equipped in providing access to financial and academic resources. For this reason, it is important to account for stress buffering effects on types of stressors that are different than those that are explicitly racial.

Of course, it is also possible that racial difference in friendship networks simply does not play a central role in the mental well-being of black adolescents. Although some 
research points to this being a potentially important relationship, other sources of social support and coping might better predict the mental health of black adolescents (Harven 2014; Noh and Kaspar 2003; Hughes et al 2014). Historical racism among the black community has led to a degree of resilience and community support in response to racism (Hughes et al 2014). Such community variables are not accounted for in the analysis. The results for Hispanic adolescents and "other race" adolescents might be non-significant due to the measures themselves. The friendship network variable from AddHealth looks at race, not ethnicity. Hispanic adolescents' racial difference scores are still calculated through the race they identify with. So, a white Hispanic would have higher racial difference if their friends were non-white. Nonetheless, it is notable that Hispanics had the highest average racial difference in friendship networks, perhaps because Hispanics can identify with a variety of race groups. Future studies should look at ethnic difference to test if having more non-Hispanic friends influences the mental well-being of Hispanic adolescents. The familismo norm in Hispanic cultures also likely plays a role, as they are more likely to go to parents and other family members for social support than other groups. The control variable of relationship with parents was significant in all the models (and is the most powerful predictor when referring to standardized coefficientsAppendix B, Table 12-13), however, so the relationship is not unique to Hispanic adolescents in this particular project.

"Other" race adolescents are an unclear group within the analysis. This category does include a significant proportion of Native American respondents, but it is otherwise hard to identify. For this reason, it is difficult to identify why the relationship between racial difference in friendship networks and the mental well-being measures were non- 
significant. Researching ethnicity further might better account for the experiences of adolescents who identify as "other."

\section{Policy Implications}

The results of this study suggest that the mental health of adolescents should be considered when looking at more integrated schools. Being in a more diverse school does not necessarily mean the friendship networks will not be segregated, in part because of the expectation of threat between in-group and out-group populations. Interracial and interethnic dialogue should be encouraged in order to diminish the influence that stereotypes have on racial attitudes. Such dialogue serves as a point of intergroup contact that might lead not only to more interracial friendships but also more effective ones. Schools should also work to address perceived prejudice in schools. White students especially may find themselves with less resources to buffer stress that results from an increased awareness of the racial prejudice that occurs against their non-white friends. Whereas minorities themselves are able to turn to same-race friends and family as a resource for advice on how to handle or respond to discrimination, white adolescents might not know who to turn to. This is not to say that white adolescents need more mental health resources than minority adolescents, but rather that an understanding of what to do when you see prejudice in action will likely aid the mental well-being of all adolescents.

The fact that diverse friendship networks are associated with reduced mental health should not suggest a need for white adolescents to have predominantly same-race friends. Rather, schools should encourage intergroup contact in order to lessen the discomfort associated with such friendships. Similarly, the stigma of interracial 
friendships extends beyond the attitudes of the students. Perceptions of such friendships outside of the school, such as the attitudes of parents, likely undermine valuable resources interracial friendship networks might otherwise be able to access. This is similar to how white women in interracial relationships experience an increase in perceived prejudice and diminished support from friends and family (Miller and Kail 2016; Yancey 2007). Such diminished support reflects societal attitudes that are in part overcome by more intergroup contact. Note that Asian adolescents, the one group with a significant positive association between racial difference in friendship networks and mental well-being, had much higher rates of interracial friendships. Familiarity thus likely plays a central role in whether or not diverse friendship networks are beneficial for adolescents.

Lastly, safe-spaces and same-race friendships are still an important resource for adolescents. In the development of identity, adolescents might seek peers similar to themselves in order to find a sense of belonging. Additionally, youth can turn to samerace friends when they experience stereotypes that attack their racial identity. Studies on immigrant children show that the most successful tend to be those who are able to both preserve the "ethnic capital" of their families and create bonds within the mainstream culture to develop a better sense of belonging (Tummala-Nara and Sathasivam-Rueckert 2016; Corona et al 2017). This balance might extend to more than just immigrant youth. Programs that encourage cultural exchange will likely help all youth find ways to find a place to "fit" within school without leading to more segregated social networks. 


\section{Limitations}

Although this analysis succeeds in its main goal of exploring racial variations in the relationship between friendships and mental well-being, limitations reduce confidence in the findings and point to areas for future research. Wave 1 of AddHealth was selected in order to focus specifically on the influence of racial difference in friendship networks among adolescents. However, because these data are cross-sectional, I cannot claim causality. I cannot rule out social selection. In the context of mental health research, social selection would mean healthier people are more likely to have interracial friendships. Other factors like education level and socioeconomic status might contribute to social selection of friendships. This is a key limitation of cross-sectional data. Making use of longitudinal data in the future would better allow us to track the direction of the relationship between racial difference in friendship networks and mental well-being.

Longitudinal data is also necessary in testing the synthesized theoretical model

(Figure 4). The stress process and contact theory are difficult to integrate without accounting for effects over time. According to my integrated theoretical model, the negative association between racial difference and mental health among white adolescents would likely diminish over time as they grow comfortable with minority friends, develop stronger ties, rethink what "whiteness" is, and break down their own separation from the "other" (Pettigrew 1998). Different stressors might arise at different points in the contact theory process. Establishing positive intergroup contact, for example, are initially impeded by higher levels of racialized anxiety related to a previous lack of exposure. Later, as contact becomes more established, members of dominant populations might have less of this anxiety but also more stress from the awareness of prejudice. This 
model can thus only be tested with the use of longitudinal data. This research project provides evidence for the potential benefits of integrating contact theory with the stress process model. The mixed results of the analysis suggest that the relationship between racially different friendship networks and mental well-being is complex but also worth further study.

In addition, the lack of a variable on psychological distress makes me unable to truly test if racial difference in friendship networks might be a buffer within the stressprocess model. This study explores whether or not racial difference might have a "main effect" on the diminished mental well-being stress-outcome. It is known that social networks--including friendships in adolescence--are a "buffering" resource that protects against poor mental health outcomes. The next step, then, is to test if friendships of difference or friendships of solidarity become a resource when adolescents are experiencing higher levels of psychological distress. Nonetheless, this research adds to the available literature on the stress process and points to the importance of studying variations not only by demographic characteristics of the subject but also by the demographic characteristics of the available social resources.

Numerous factors resulted in a diminished sample size that increases the margin of error without the study's findings. First, only the public-use AddHealth data set was available. The decision to use the public-use data was out of convenience, but future studies should expand to using the full data set. The full data set has over 90,000 responses to the in-home survey and multiple levels of data. Secondly, although the data set is nationally representative, Asian adolescents, who turned out to be a key demographic in the study of the relationship between friendship and mental well-being, 
only made up $6 \%$ of the available public-use data after reducing the sample to include only adolescent's without missing variables. However, the fact that the Asian identification demographic variable and the Asian X racial difference moderator were significant indicators of both mental health and self-esteem despite the low sample size points to the necessity of a more in-depth exploration of the importance of friendship among Asian respondents.

The relationship with parents variable was created using two measures (relationship with mother and relationship with father) and condensed into one. Keeping these variables isolated could illustrate important differences in the parents gender, but these variables had to be collapsed in my analysis. Without doing so, many adolescents would be excluded from analysis for legitimate non-answers to the questions, such as being raised by a single parent. The importance of a relationship with parents may also vary for those who have only one parent.

The quality friendship variable showed a significant but small relationship in the models predicting adolescent self-esteem, but the measure is likely unreliable. Questions in the constructed friendship quality scale were largely about frequency of contact and emotional dependence, such as "did you spend time with [friend] on the weekend" and "did you talk to [friend] about a problem in the last seven days." Questions limited the time frame to a week, which might be too limiting to assess friendship quality. In addition, most of the questions are concerned with shared activity, and this is not necessarily the same thing as the perceived "quality" of the friend. I only included the friendship quality of the relationship between the respondent and their reported "best" male and "best" female friend to account for this limitation, but there were still a large 
amount of respondents who had a 0 score on the friendship quality scale. It is unclear why there were many "0" scores on friendship quality, but limiting the scale to contact in the last seven days and to just the "best" friends are at least partly to blame.

The available information of friendship networks—although unique—is also limited. Respondents were allowed to report up to 5 male friends and 5 female friends, but were not required to do so. Additionally, they were not required to only report friends within their paired-school network. As such, some respondents may have reported only one or two friends while others reported a full ten. As an example, an adolescent who reported only friends of the same race within their paired-school network but had other different-race friends outside the network would still receive a $0 \%$ score on the racial difference in friendship networks variable. As such, friendship data cannot be generalized to describe the full extent of an adolescent's friendship networks. The number of friends an adolescent has might also have a relationship with the racial difference of friendship network variable that remains unexplored in this analysis, and the quality friendship variable is likely not enough to account for this. However, I would argue that limiting represented friends to within the school network increases the likelihood that the reported friends have routine contact with the respondent. Such routine contact is essential to contact theory, a core framework in my analysis.

Descriptive statistics in Table 1 report skewed data. Mental health measures are often positively skewed, with average-to-high mental health and self-esteem assessments to be the norm. As such, the mean of self-reported mental health scores is 39.07 out of 50; self-esteem, 24.76 out of 30 . In order to view the results with the skew corrected, I cubed the data and exponentiated cubed coefficients. Taking higher powers is a 
transformation technique that makes negatively skewed data more symmetric and thus easier to interpret. This supplemental analysis had no substantively different findings in comparison to the analysis presented here. There is also a possibility that the association between racial difference within friendship networks and my two mental well-being measures (CES-D and self-esteem) is a curvilinear relationship. In fact, no respondent reported a racial difference score greater than $76 \%$, and most respondents reported racial difference between $20 \%-60 \%$. I ran a scatterplot to confirm linearity, but future studies should nonetheless use the full Add Health sample to assess if the relationship is in fact curvilinear, with their being an ideal "balance" between racially similar and racially different friends.

Lastly, future studies should consider doing a multi-level analysis that also includes school factors such as geographic region and racial diversity within school. Such variables likely influence the possibility of having racially different friendship networks. Such variables would also allow us to further investigate the contact theory explanation for the higher mental well-being of Asian adolescents who have racially different friendship networks by checking to see if Asians are more likely than other groups to attend diverse schools. I also cannot completely rule out the influence of school clusters within the data set. Many of the Asian respondents in the come from a select few of the schools within the Add Health data set. As such, I cannot claim that the positive association between racial difference in friendship networks and mental well-being among Asian adolescents is generalizable to all Asian adolescents within the United States. The grand sampling weight included in the analysis accounts for issues related to individual characteristics, but cluster weights would need to be included as well in order 
to correct this potential issue. SPSS is not the ideal analysis software for including the many weighted measures or cluster designs in Add Health. When weights are added, SPSS oftentimes artificially lowers the standard errors, making some results look statistically significant when they actually aren't. As such, the results of this study should be confirmed by running regressions in data software that properly handles weights such as STATA or SAS. Examining the effect size of the coefficients in my models rather than their statistical significance minimizes some of the concerns regarding artificially small standard errors.

\section{Key Findings}

This study adds to the body of literature on friendships, the stress process, and contact theory by investigating how the race of an adolescent's friends might impact their mental well-being. As I hypothesized, the relationship between racial difference in friendship networks and mental well-being varied depending on the race of the adolescent. Asian adolescents tended to have higher mental well-being if they had higher racial difference in their friendship networks; white adolescents, on the other hand, had lower mental well-being when the same occurred. These differences shed light on the continued importance of investigating the role of demographic characteristics in studies on stress and mental health. As researchers, we cannot assume that what occurs among white populations also occurs among different minority populations. Similarly, we cannot assume that "social support," a powerful mediator in the stress process, is somehow a "color-blind" phenomenon that all people experience equally and treat similarly. 


\section{$\underline{\text { References }}$}

Allport, Gordon W. 1954. The Nature of Prejudice: 25th Anniversary Edition. New York: Perseus Books Publishing, L.L.C.

Baiocco, Roberto, Federica Santamaria, Antonia Longiro, Salvatore Ioverno, Emma Baumgartner, and Fiorenzo Laghi. 2014. "Beyond Similarities: Cross-Gender and Cross-Orientation Best Friendship in a Sample of Sexual Minority and Heterosexual Young Adults." Sex Roles 70(3-4): 110-121.

Beiser, Morton. 1974. "Components and Correlates of Well-Being." Journal of Health and Social Behavior 15(4): 320-27.

Bratter, Jenifer L. and Karl Eschbach. 2006. "'What about the couple?' Interracial marriage and psychological distress. Social Science Research 35(4): $1025-$ 47.

Burke, Jessica L. 2015. "Investigating Psychological Distress in Latino Romantic Relationships." Race, Gender \& Class 22(3/4): 172-94.

Corona, Rosalie, Vivian M. Rodríguez, Shelby E. Mcdonald, Efren Velazquez, Adriana Rodríguez, Vanessa E. Fuentes. 2017. "Associations between Cultural Stressors, Cultural Values, and Latina/o College Students' Mental Health." Journal of Youth and Adolescence 46(1): 63-77.

Chen, Ping and Kim Chantala. 2014. "Guidelines for Analyzing Add Health Data." Carolina Population Center, University of North Carolina at Chapel Hill. Retrieved April 2017.

(http://www.cpc.unc.edu/projects/addhealth/documentation/guides)

Doyle, Jamie M. 2007. "The physical and mental health of multiracial adolescents in the Unites States." Dissertation Abstracts International, A: The Humanities and Social Sciences 68(07): 1-110.

Durkee, Miles I., and Joanna L. Williams. 2015. "Accusations of Acting White: Links to Black Students' Racial Identity and Metal Health." The Journal of Black Psychology: 41(1): 26-48.

Durkheim, Emile. 2012. Suicide: A Study in Sociology. Translated by John A. Spaulding and George Simpson. Snowball Publishing.

Easterbrook, Matthew J. and Vivian L. Vignoles. 2015. "When friendship formation goes down the toilet: Design features of shared accommodation influence interpersonal bonds and well-being." British Journal of Social Psychology 54(1):125-39. 
Elliot, Marta. "Gender Differences in the Determinants of Distress, Alcohol Misuse, and Related Psychiatric Disorders." Society and Mental Health 3(2): 96-113.

Ericson, Erik. 1950. Childhood and Society. New York, NY: W.W. Norton \& Company, Inc.

Goza, Franklin and Igor Ryabov. 2009. "Adolescents' Educational Outcomes: Racial and Ethnic Variations in Peer Network Importance." Journal of Youth And Adolescence 38: 1264-79.

Harven, Aletha Marie. 2014. "Black and Latino adolescents' perceptions of racial discrimination and school adjustment: Parent educational advocacy and friendship support as protective factors." ProQuest Dissertations and Theses: 98-

Hill Collins, Patricia. 2000. Black Feminist Thought: Knowledge, Consciousness, and the Politics of Empowerment (2nd ed.). Great Britain: Routledge.

Hughes, Michael, K. Jill Kiecolt, and Verna M. Keith. 2014. "How Racial Identity Moderates the Impact of Financial Stress on Mental Health among African Americans." Society and Mental Health 4(1): 38-54.

Kao, Grace and Kara Joyner. 2004. "Do Race and Ethnicity Matter Among Friends? Activities among Interracial, Interethnic, and Intraethnic Adolescent Friends." The Sociological Quarterly 45(3): 557-73.

Kivijarvi, Annti. 2015. "Fragility of leisure ties between ethnic minority and majority youth--an empirical case from Finland." Leisure Studies 34(2): 150-165.

Knifsend, Casey Anne. 2013. "Extracurricular Involvement, Friendships, and Social Identity Development in Ethnically Diverse Middle Schools." Dissertation Abstracts International A: The Humanities and Social Sciences. 1-104.

Kosuke, Sato, Masaki Yuki, and Vinai Norasakkunkit. 2014. "A Socio-Ecological Approach to Cross-Cultural Differences in the Sensitivity to Social Rejection: The Partially Mediating Role of Relational Mobility." Journal of Cross-Cultural Psychology 45(10): 1549-60.

Miller, Byron and Ben L. Kail. 2016. "Exploring the Effects of Spousal Race on the Selfrated Health of Intermarried Adults." Sociological Perspectives 59(3): 604-18.

Mossakowski, Krysia N. and Wei Zhang. 2014. "Does Social Support Buffer the Stress of Discrimination and Reduce Psychological Distress Among Asian Americans?" Social Psychology Quarterly 77(3): 273-95. 
Noh, Samuel and Violet Kaspar. 2003. "Perceived Discrimination and Depression: Moderating Effects of Coping, Acculturation, and Ethnic Support." American Journal of Public Health 93: 232-38.

Pearlin, Leonard I. 1999. "Stress and Mental Health: A Conceptual Overview." Pp.16175, in A Handbook for the Study of Mental Health: Social Contexts, Theories, and Systems, edited by Allan V. Horwitz and Teresa L. Scheid. New York: Cambridge University Press.

Pettigrew, Thomas F. 1998. "Intergroup Contact Theory." Annual Review of Psychology 49:65-85

Powers, Daniel A. and Christopher G. Ellison. 1995. "Interracial Contact and Black Racial Attitudes: The Contact Hypothesis and Selectivity Bias." Social Forces(1): 205-226.

Proctor, Carmel, Alex P. Linley, and John Maltby. 2010. "Very Happy Youths: Benefits of Very High Life Satisfaction Among Adolescents." Social Indicators Research 98(3): 519-32.

Radloff, Lenore S. 1977. "The CES-D Scale: A Self-Report Depression Scale for Research in the General Population." Applied Psychological Measurement 1(3): 385-401.

Ryabov, Igor. 2011. "Adolescent academic outcomes in school context: Network effects Reexamined." Journal of Adolescence 34: 915-27.

Smith, Rhiannon L. 2013. "Youths' Cross-ethnic Friendships and Associations with Socioemotional Adjustment." Dissertation Abstracts International, B: Sciences and Engineering 74(04): 1-8.

Soto, José A., Nana A. Dawson-andoh, Dawn P. Witherspoon. 2016. "An Ecological Approach to Racial Environments and Their Relationship to Mental Health." Race and Social Problems 8(3): 209-221.

Thoits, Peggy A. and Bruce G. Link. 2016. "Stigma Resistance and Well-being among People in Treatment for Psychosis. Society and Mental Health 6(1): 1-20.

Thompson, Franklin T. and Daniel U. Levine. 1997. "Examples of Easily Explainable Suppressor Variables in Multiple Regression Research." Multiple Linear Regression Viewpoints 24: 11-13.

Tummala-Nara, Pratyusha and Nina Sathasivam-Rueckert. 2016. "The Experience of Ethnic and Racial Group Membership Among Immigrant-Origin Adolescents." Journal of Adolescent Research 31(3): 299-342. 
Turner, R. Jay. 1999. "Social Support and Coping." Pp.198-210 in A Handbook for the Study of Mental Health: Social Contexts, Theories, and Systems, edited by Allan V. Horwitz and Teresa L. Scheid. New York: Cambridge University Press.

Ueno, Koji. 2009. "Same-Race Friendships and School Attachment: Demonstrating the Interaction Between Personal Network and School Composition." Sociological Forum 24(3): 515-537.

Yancey, George. 2007. "Experiencing Racism: Differences in the Experiences of Whites Married to Blacks and Non-Black Racial Minorities." Journal of Comparative Family Studies 38(2): 197-213.

Yin, Ke Li, Jia Mei He, and Yan Fen Fu. 2013. "Positive Mental Health: Measurement, Prevalence, and Correlates in a Chinese Cultural Context." Pp. 111-33 Mental Well-Being: International Contributions to the Study of Positive Mental Health, edited by Corey L.M. Keyes. Springer.

Zhang, Rui and Liman Man Wai Li. 2014. "The Acculturation of Relational Mobility: An Investigation of Asian Canadians." Journal of Cross-Cultural Psychology 45(9): $1390-1410$ 


\section{Appendix A: Measures}

\section{Table 9, Key Variables}

\begin{tabular}{|c|c|c|c|c|}
\hline & Questions & Coding & Ranges & $\begin{array}{l}\text { Alpha } \\
\text { Coeffecient (if } \\
\text { one) }\end{array}$ \\
\hline \multirow[t]{20}{*}{$\begin{array}{l}\text { Mental } \\
\text { Health } \\
\text { (CES-D } \\
\text { scale) }\end{array}$} & "In the last two weeks..." & $\begin{array}{l}\text { Scales were reverse coded } \\
\text { such that the lowest amoung } \\
\text { of depressive symptoms } \\
\text { reflected the highest score (50) }\end{array}$ & {$[0,50]$} & 0.915 \\
\hline & $\begin{array}{l}\text { "you were bothered by } \\
\text { things that usually don't } \\
\text { bother you" }\end{array}$ & $\begin{array}{l}\text { 0: "Most of the time or all of the } \\
\text { time" }\end{array}$ & {$[0,3]$} & \\
\hline & & 1: "A lot of the time" & & \\
\hline & & 2: "Sometimes" & & \\
\hline & & 3:"Never or rarely." & & \\
\hline & $\begin{array}{l}\text { "you didn't feel like } \\
\text { eating, your appetite } \\
\text { was poor" }\end{array}$ & $" \ldots "$ & {$[0,3]$} & \\
\hline & $\begin{array}{l}\text { "you felt that you could } \\
\text { not shake off the blues, } \\
\text { even with help from your } \\
\text { family and your friends" }\end{array}$ & "..." & $" \ldots "$ & \\
\hline & $\begin{array}{l}\text { "you had trouble } \\
\text { keeping your mind on } \\
\text { what you were doing" }\end{array}$ & "..." & $" \ldots "$ & \\
\hline & "you felt depressed" & "..." & "..." & \\
\hline & $\begin{array}{l}\text { "you felt that you were } \\
\text { too tired to do things" }\end{array}$ & "..." & $" \ldots "$ & \\
\hline & "you felt fearful" & "..." & "..." & \\
\hline & $\begin{array}{l}\text { "you talked less than } \\
\text { usual" }\end{array}$ & "..." & $" \ldots "$ & \\
\hline & "you felt lonely" & "..." & "..." & \\
\hline & $\begin{array}{l}\text { "people were unfriendly } \\
\text { to you" }\end{array}$ & $" \ldots "$ & $" \ldots "$ & \\
\hline & "you felt sad" & "..." & "..." & \\
\hline & $\begin{array}{l}\text { "you felt that people } \\
\text { disliked you" }\end{array}$ & $" \ldots "$ & "..." & \\
\hline & $\begin{array}{l}\text { "it was hard to get } \\
\text { started doing things" }\end{array}$ & "..." & "..." & \\
\hline & $\begin{array}{l}\text { "you felt life was not } \\
\text { worth living" }\end{array}$ & "..." & $" \ldots "$ & \\
\hline & $\begin{array}{l}\text { "you felt you were just } \\
\text { as good as other } \\
\text { people" }\end{array}$ & 0: "Never or rarely" & "..." & \\
\hline & & 1: "Sometimes" & "..." & \\
\hline
\end{tabular}




\begin{tabular}{|c|c|c|c|c|}
\hline & & 2: "A lot of the time" & "..." & \\
\hline & & $\begin{array}{l}\text { 3: "Most of the time or all of the } \\
\text { time" }\end{array}$ & "..." & \\
\hline & $\begin{array}{l}\text { "you felt hopeful about } \\
\text { the future" }\end{array}$ & $" \ldots "$ & $" \ldots "$ & \\
\hline & "you were happy" & $" \ldots "$ & $" \ldots "$ & \\
\hline & "you enjoyed life" & $" \ldots "$ & $" \ldots "$ & \\
\hline \multirow[t]{11}{*}{$\begin{array}{l}\text { Modified } \\
\text { Rosenburg } \\
\text { Self- } \\
\text { Esteem }\end{array}$} & $\begin{array}{l}\text { "Do you agree or } \\
\text { disagree with the } \\
\text { following statement? }\end{array}$ & $\begin{array}{l}\text { Measure is modified in that it } \\
\text { does not contain all } 10 \text { items. } \\
\text { Responses are coded such } \\
\text { that higher scores represent } \\
\text { higher self-esteem }\end{array}$ & {$[6,30]$} & 0.845 \\
\hline & $\begin{array}{l}\text { "I feel like I am doing } \\
\text { everything just about } \\
\text { right" }\end{array}$ & 1: Strongly disagree & {$[1,5]$} & \\
\hline & & 2: Disagree & & \\
\hline & & 3: Neither agree nor disagree & & \\
\hline & & 4: Agree & & \\
\hline & & 5: Strongly Agree & & \\
\hline & $\begin{array}{l}\text { "You feel loved and } \\
\text { wanted" }\end{array}$ & $" \ldots "$ & {$[1,5]$} & \\
\hline & $\begin{array}{l}\text { "You feel socially } \\
\text { accepted" }\end{array}$ & $" \ldots "$ & $" \ldots "$ & \\
\hline & $\begin{array}{l}\text { "You have a lot of good } \\
\text { qualities" }\end{array}$ & "..." & $" \ldots "$ & \\
\hline & $\begin{array}{l}\text { "You have a lot to be } \\
\text { proud of" }\end{array}$ & $" \ldots "$ & $" \ldots "$ & \\
\hline & $\begin{array}{l}\text { "You like yourself just } \\
\text { the way you are" }\end{array}$ & "..." & $" \ldots "$ & \\
\hline $\begin{array}{l}\text { Racial } \\
\text { Diversity } \\
\text { in } \\
\text { Friendship } \\
\text { Networks } \\
\end{array}$ & $\begin{array}{l}\text { N/A, higher score } \\
\text { signifies a more diverse } \\
\text { friendship network }\end{array}$ & $\begin{array}{l}\text { Compiled on AddHealth based } \\
\text { on friendship reporting data; } \\
\text { the network variable that } \\
\text { includes all reported friends } \\
\text { was used (friendship does not } \\
\text { have to be recpiprocated to be } \\
\text { included }\end{array}$ & {$[0,76.39]$} & \\
\hline \multirow[t]{2}{*}{$\begin{array}{l}\text { Friendship } \\
\text { Reporting } \\
\text { Question }\end{array}$} & $\begin{array}{l}\text { "List your closest male } \\
\text { friends. List your best } \\
\text { male friend first, then } \\
\text { your next best friend } \\
\text { and so on. Girls may } \\
\text { include boys who are } \\
\text { friends and boyfriends." }\end{array}$ & & & \\
\hline & $\begin{array}{l}\text { "List your closest female } \\
\text { friends. List your best } \\
\text { female friend first, then } \\
\text { your next best friend } \\
\text { and so on. Boys may } \\
\text { include girls who are }\end{array}$ & & & \\
\hline
\end{tabular}


Table 10, Demographic Characteristics

\begin{tabular}{|c|c|c|c|}
\hline & Questions & Coding & Ranges \\
\hline $\begin{array}{l}\text { Hispanic } \\
\text { (Ethnicity } \\
\text { Variable) }\end{array}$ & $\begin{array}{l}\text { "Are you of Hispanic } \\
\text { or Spanish origin?" }\end{array}$ & 0: No & {$[0,1]$} \\
\hline & & 1: Yes & \\
\hline $\begin{array}{l}\text { Race } \\
\text { Variables }\end{array}$ & $\begin{array}{l}\text { "What is your race? } \\
\text { If you are more than } \\
\text { one race, you may } \\
\text { choose more than } \\
\text { one" }\end{array}$ & & \\
\hline \multirow[t]{2}{*}{ White } & & 0: not marked & {$[0,1]$} \\
\hline & & 1: marked & \\
\hline $\begin{array}{l}\text { Black or } \\
\text { African } \\
\text { American }\end{array}$ & "..." & "..." & $" \ldots "$ \\
\hline $\begin{array}{l}\text { Asian or } \\
\text { Pacific } \\
\text { Islander }\end{array}$ & $" \ldots "$ & $" \ldots "$ & $" \ldots "$ \\
\hline $\begin{array}{l}\text { Other + } \\
\text { Native } \\
\text { American }\end{array}$ & "..." & $\begin{array}{l}\text { The Native American and Other categories were } \\
\text { combined because of the small sample size. If both } \\
\text { Native American and Other were selected, the } \\
\text { respondent was not double-counted (range still 0-1) }\end{array}$ & "..." \\
\hline $\begin{array}{l}\text { Biological } \\
\text { Sex }\end{array}$ & $\begin{array}{l}\text { "Interviewer, please } \\
\text { confirm that R's sex } \\
\text { is male (female). Ask } \\
\text { if necessary. }\end{array}$ & 1: male & {$[1,2]$} \\
\hline & & 2: female & \\
\hline
\end{tabular}

Table 11, Control Variables

\begin{tabular}{|l|l|l|l|l|}
\hline & Questions & Coding & Ranges & $\begin{array}{l}\text { Alpha } \\
\text { Coefficient (if } \\
\text { any) }\end{array}$ \\
\hline $\begin{array}{l}\text { Friendship } \\
\text { Quality (mean } \\
\text { scale) }\end{array}$ & "in the last seven \\
days..." & $\begin{array}{l}\text { Index is a mean scale } \\
\text { measuring closeness to the } \\
\text { respondents best male and } \\
\text { best female friend }\end{array}$ & {$[0,1]$} & \\
\hline & "you went to their & 0:no & {$[0,1]$} & 0.825 \\
\hline
\end{tabular}




\begin{tabular}{|c|c|c|c|c|}
\hline & house" & & & \\
\hline & & 1: yes & & \\
\hline & $\begin{array}{l}\text { "you met them after } \\
\text { school to hang out or } \\
\text { go somewhere" }\end{array}$ & $" \ldots "$ & {$[0,1]$} & \\
\hline & $\begin{array}{l}\text { "you spent time with } \\
\text { them last weekend" }\end{array}$ & $" \ldots "$ & {$[0,1]$} & \\
\hline & $\begin{array}{l}\text { "you talked with them } \\
\text { about a problem" }\end{array}$ & $" \ldots "$ & {$[0,1]$} & \\
\hline & $\begin{array}{l}\text { "you talked to them on } \\
\text { the telephone" }\end{array}$ & $" \ldots "$ & {$[0,1]$} & \\
\hline \multirow[t]{6}{*}{ General Health } & $\begin{array}{l}\text { "In general, how is your } \\
\text { health? Would you } \\
\text { say... }\end{array}$ & $\begin{array}{l}\text { Reversed Coded so high } \\
\text { scores represent better } \\
\text { mental health }\end{array}$ & {$[1-5]$} & \\
\hline & & 1: poor & & \\
\hline & & 2: fair & & \\
\hline & & 3: good & & \\
\hline & & 4: very good & & \\
\hline & & 5: excellent & & \\
\hline \multirow[t]{5}{*}{ Hobbies } & $\begin{array}{l}\text { "During the past week, } \\
\text { how many times did } \\
\text { you do hobbies, such } \\
\text { as collecting baseball } \\
\text { cards, playing a } \\
\text { musical instrument, } \\
\text { reading, or doing arts } \\
\text { and crafts?" }\end{array}$ & & {$[0,3]$} & \\
\hline & & $0:$ not at all & & \\
\hline & & 1: 1 or 2 times & & \\
\hline & & 2: 3 or 4 times & & \\
\hline & & 3: 5 or more times & & \\
\hline $\begin{array}{l}\text { Relationship } \\
\text { with Parents } \\
\text { (Mean of two } \\
\text { Variables) }\end{array}$ & & $\begin{array}{l}\text { In order to make sure that the } \\
\text { many respondents with a } \\
\text { legitimate reason to skip } \\
\text { either the "relationship with } \\
\text { mother" and "relationship with } \\
\text { father" questions, the scores } \\
\text { of the two measures were } \\
\text { indexed to create a small, two } \\
\text { item mean scale }\end{array}$ & & $\begin{array}{l}0.606 \text { (likely } \\
\text { lower because } \\
\text { of the } \\
\text { "legitimate } \\
\text { skip" issue }\end{array}$ \\
\hline \multirow[t]{4}{*}{$\begin{array}{l}\text { Relationship } \\
\text { with Mother }\end{array}$} & $\begin{array}{l}\text { "Overall, you are } \\
\text { satisfied with your } \\
\text { relationship with your } \\
\text { mother" }\end{array}$ & $\begin{array}{l}\text { Reverse coded such that } \\
\text { higher values represent a } \\
\text { more satisfied relationship }\end{array}$ & {$[1,5]$} & \\
\hline & & 1: strongly disagree & & \\
\hline & & 2: disagree & & \\
\hline & & 3: neither agree nor disagree & & \\
\hline
\end{tabular}




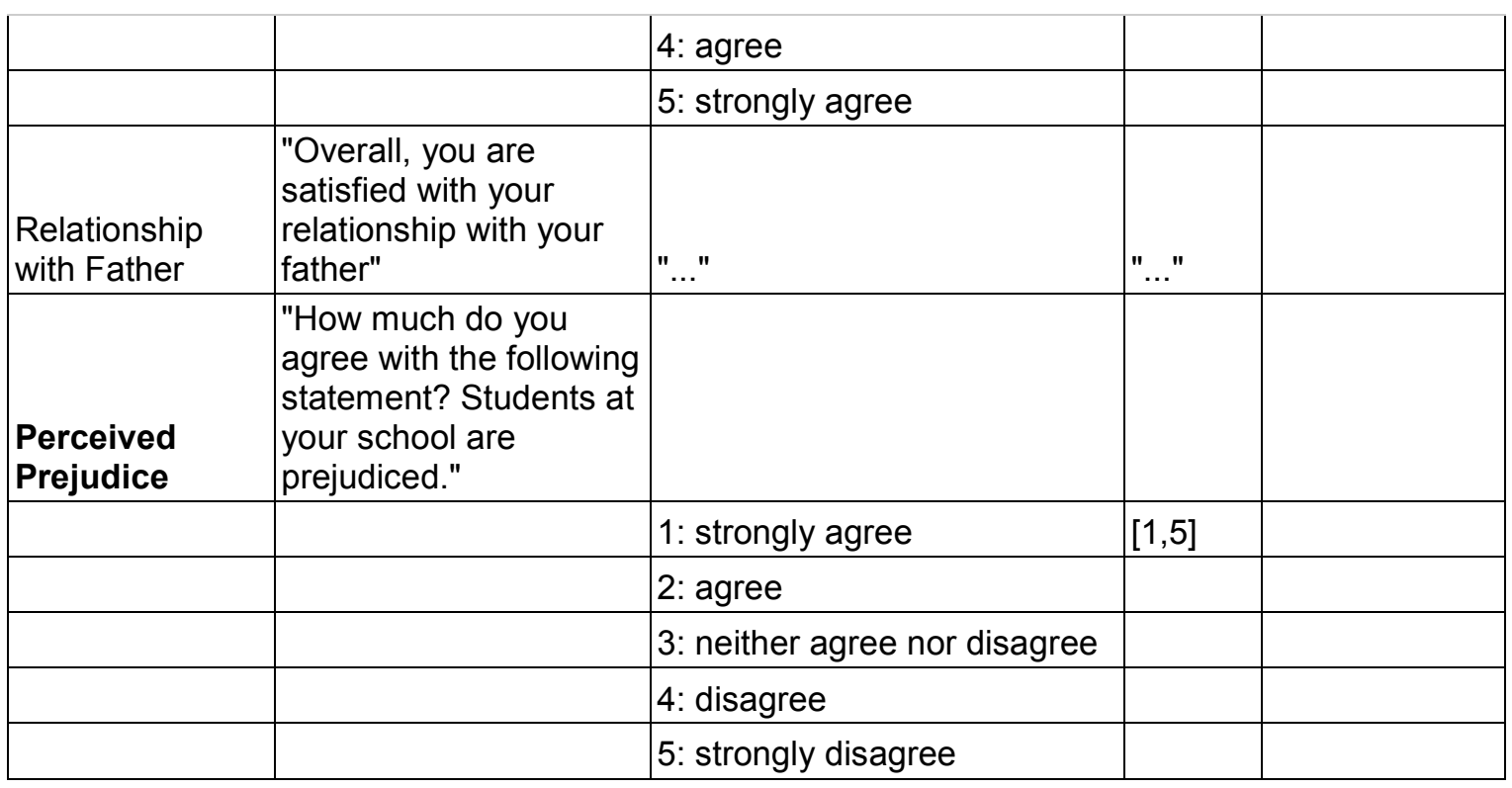


Appendix B: Supplemental Information

Table 12: Crosstabs of Race and Ethnicity Variables

\begin{tabular}{|c|c|c|}
\hline Race & Hispanic(\% of Total Hispanic) & $\begin{array}{l}\text { Non-Hispanic Ethnicity(\% of } \\
\text { Total Non-Hispanic) }\end{array}$ \\
\hline White & $383(52 \%)$ & $3929(67 \%)$ \\
\hline Black & $35(5 \%)$ & $1583(28 \%)$ \\
\hline Asian & $13(2 \%)$ & $256(4 \%)$ \\
\hline Native American & $54(7 \%)$ & $181(3 \%)$ \\
\hline "Other" Race & $350(48 \%)$ & $74(1 \%)$ \\
\hline Total & 731 & 57 \\
\hline
\end{tabular}

Appendix B, Table 12, is included to show what race Hispanic adolescents report within the public-use Wave I data. Because adolescents were able to report more than one race, the percentages reported here exceed $100 \%$. In this table "other" race is not collapsed with the Native American variable. These two were later collapsed due to the small sample of Native Americans within the sample. 
Standardized Coefficients

Table 13: Standardized Coefficients of Significant Variables in the Linear Regression Model Predicting Adolescent Mental Health (in Model 4) Standardized Coefficients Beta

\begin{tabular}{lc} 
Racial Difference & $-0.06^{* * *}$ \\
Black & $-0.12^{* * *}$ \\
Asian & $-0.17^{* * *}$ \\
Biological Sex & $-0.04^{* *}$ \\
Relationship With Parents & $0.25^{* * *}$ \\
General Health & $0.22^{* * *}$ \\
Hobbies & $0.06^{* * *}$ \\
Students are Prejudiced & $-0.16^{* * *}$ \\
Asian*Racial Difference & $0.13^{* * *}$ \\
\multicolumn{1}{l}{$\mathrm{n}=4110 *(\mathrm{p} \leq 0.05),{ }^{* *}(\mathrm{p} \leq 0.01),{ }^{* * *}(\mathrm{p} \leq 0.001)$}
\end{tabular}

Table 14: Standardized Coeffecients of Significant Variables in the Linear Regression Model Predicting Adolescent Self-Esteem (in Model 4)

Standardized Coefficients Beta

$\begin{array}{lc}\text { Black } & 0.12^{* * *} \\ \text { Asian } & -0.13^{* * *} \\ \text { Biological Sex } & -0.09^{* * *} \\ \text { Relationship With Parents } & 0.39^{* * *} \\ \text { General Health } & 0.25^{* * *} \\ \text { Hobbies } & 0.03^{*} \\ \text { Friendship Quality } & 0.06^{* * *} \\ \text { Students are Prejudiced } & -0.05^{* * *} \\ \text { Asian*Racial Difference } & 0.09^{* * *} \\ n=4114{ }^{*}(p \leq 0.05),{ }^{* *}(p \leq 0.01),{ }^{* * *}(p \leq 0.001)\end{array}$


Table 15: Linear Unstandardized Coefficients from Linear Regression Models Predicting Black Adolescent Mental Health

\begin{tabular}{|c|c|c|c|}
\hline & \multicolumn{2}{|c|}{ Model 1 Model 2} & \multirow{2}{*}{$\begin{array}{l}\text { Model } 3 \\
\text { B }\end{array}$} \\
\hline & B & B & \\
\hline \multirow[t]{2}{*}{ (constant) } & 39.234 & 40.051 & 30.152 \\
\hline & $(0.371)$ & $(0.447)$ & $(1.282)$ \\
\hline \multirow[t]{2}{*}{ Racial Difference } & -0.004 & -0.004 & -0.003 \\
\hline & $(0.010)$ & $(0.010)$ & $(0.009)$ \\
\hline \multirow[t]{2}{*}{ Biological Sex } & & $-1.452^{* * *}$ & -0.550 \\
\hline & & $(0.446)$ & $(0.426)$ \\
\hline \multirow[t]{2}{*}{ Relationship with Parents } & & & $2.042^{* * *}$ \\
\hline & & & $(0.235)$ \\
\hline \multirow[t]{2}{*}{ General Health } & & & $1.650^{\star * *}$ \\
\hline & & & $(0.234)$ \\
\hline \multirow[t]{2}{*}{ Hobbies } & & & 0.224 \\
\hline & & & $(0.200)$ \\
\hline \multirow[t]{2}{*}{ Friendship Quality } & & & 0.780 \\
\hline & & & $(0.718)$ \\
\hline \multirow[t]{2}{*}{ Students are Prejudiced } & & & $-1.088^{* * *}$ \\
\hline & & & $(0.170)$ \\
\hline R-Squared & -0.001 & 0.008 & 0.154 \\
\hline \multicolumn{4}{|c|}{$N=1099{ }^{*}(p \leq 0.05),{ }^{* *}(p \leq 0.01),{ }^{* * *}(p \leq 0.001)$} \\
\hline
\end{tabular}


Table 16: Linear Unstandardized Coefficients from Linear Regression Models Predicting Black Adolescent Self-Esteem

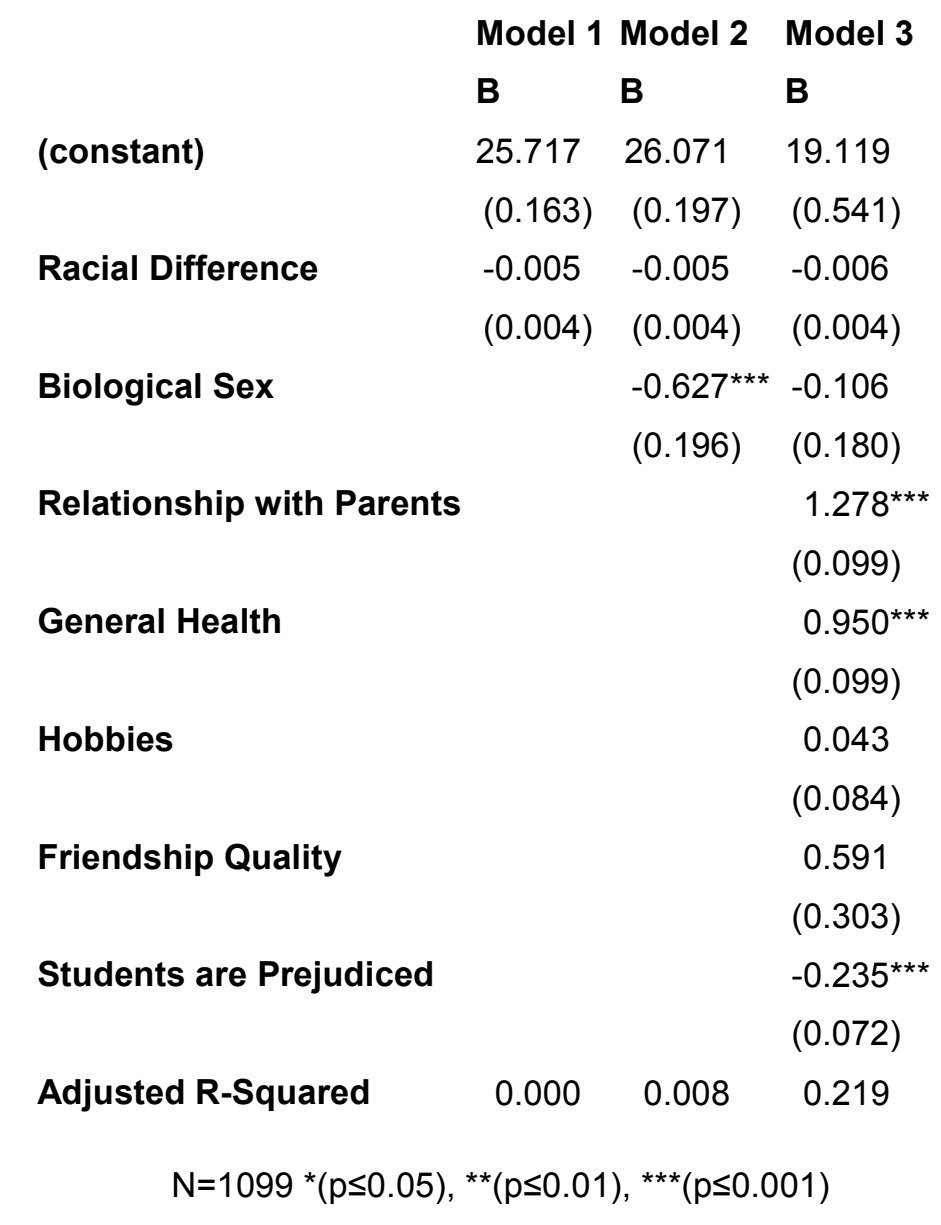


Table 17: Linear Unstandardized Coefficients from Linear Regression Models Predicting "Other" Adolescent Mental Health

\begin{tabular}{|c|c|c|c|}
\hline & \multicolumn{2}{|c|}{ Model 1 Model 2} & \multirow{2}{*}{$\begin{array}{l}\text { Model } 3 \\
\text { B }\end{array}$} \\
\hline & B & B & \\
\hline \multirow[t]{2}{*}{ (constant) } & 37.797 & 39.418 & 28.760 \\
\hline & $(0.949)$ & $(1.055)$ & $(2.511)$ \\
\hline \multirow[t]{2}{*}{ Racial Difference } & -0.013 & -0.011 & -0.004 \\
\hline & $(0.020)$ & $(0.020)$ & $(0.018)$ \\
\hline \multirow[t]{2}{*}{ Biological Sex } & & $-2.927^{* * *}$ & $-1.697^{* * *}$ \\
\hline & & $(0.879)$ & $(0.814)$ \\
\hline \multirow[t]{2}{*}{ Relationship with Parents } & & & $2.537^{* * *}$ \\
\hline & & & $(0.431)$ \\
\hline \multirow[t]{2}{*}{ General Health } & & & $1.744^{* * *}$ \\
\hline & & & $(0.406)$ \\
\hline \multirow[t]{2}{*}{ Hobbies } & & & $0.992^{* *}$ \\
\hline & & & $(0.376)$ \\
\hline \multirow[t]{2}{*}{ Friendship Quality } & & & 1.862 \\
\hline & & & $(1.308)$ \\
\hline \multirow[t]{2}{*}{ Students are Prejudiced } & & & $-1.697^{* * *}$ \\
\hline & & & $(0.331)$ \\
\hline Adjusted R-Squared & -0.002 & 0.027 & 0.239 \\
\hline \multicolumn{4}{|c|}{$N=347(p \leq 0.05),{ }^{* *}(p \leq 0.01),{ }^{* * *}(p \leq 0.001)$} \\
\hline
\end{tabular}


Table 18: Linear Unstandardized Coefficients from Linear Regression Models Predicting "Other" Adolescent Self-Esteem

\begin{tabular}{|c|c|c|}
\hline Model 1 & Model 2 & Model 3 \\
\hline B & B & B \\
\hline 24.637 & 25.176 & 16.504 \\
\hline$(0.436)$ & $(0.489)$ & (1.105) \\
\hline-0.009 & -0.009 & -0.006 \\
\hline (0.009) & $(0.009)$ & $(0.008)$ \\
\hline & $-0.965^{\star}$ & -0.429 \\
\hline & $(0.406)$ & $(0.360)$ \\
\hline & & $1.859^{* * *}$ \\
\hline & & $(0.190)$ \\
\hline & & $0.996^{\star * \star}$ \\
\hline & & $(0.179)$ \\
\hline & & 0.015 \\
\hline & & $(0.166)$ \\
\hline & & 0.759 \\
\hline & & $(0.576)$ \\
\hline & & -0.197 \\
\hline & & $(0.146)$ \\
\hline 0.000 & 0.013 & 0.293 \\
\hline
\end{tabular}


Table 19: Linear Unstandardized Coefficients from Linear Regression Models Predicting Hispanic Adolescent Mental Health

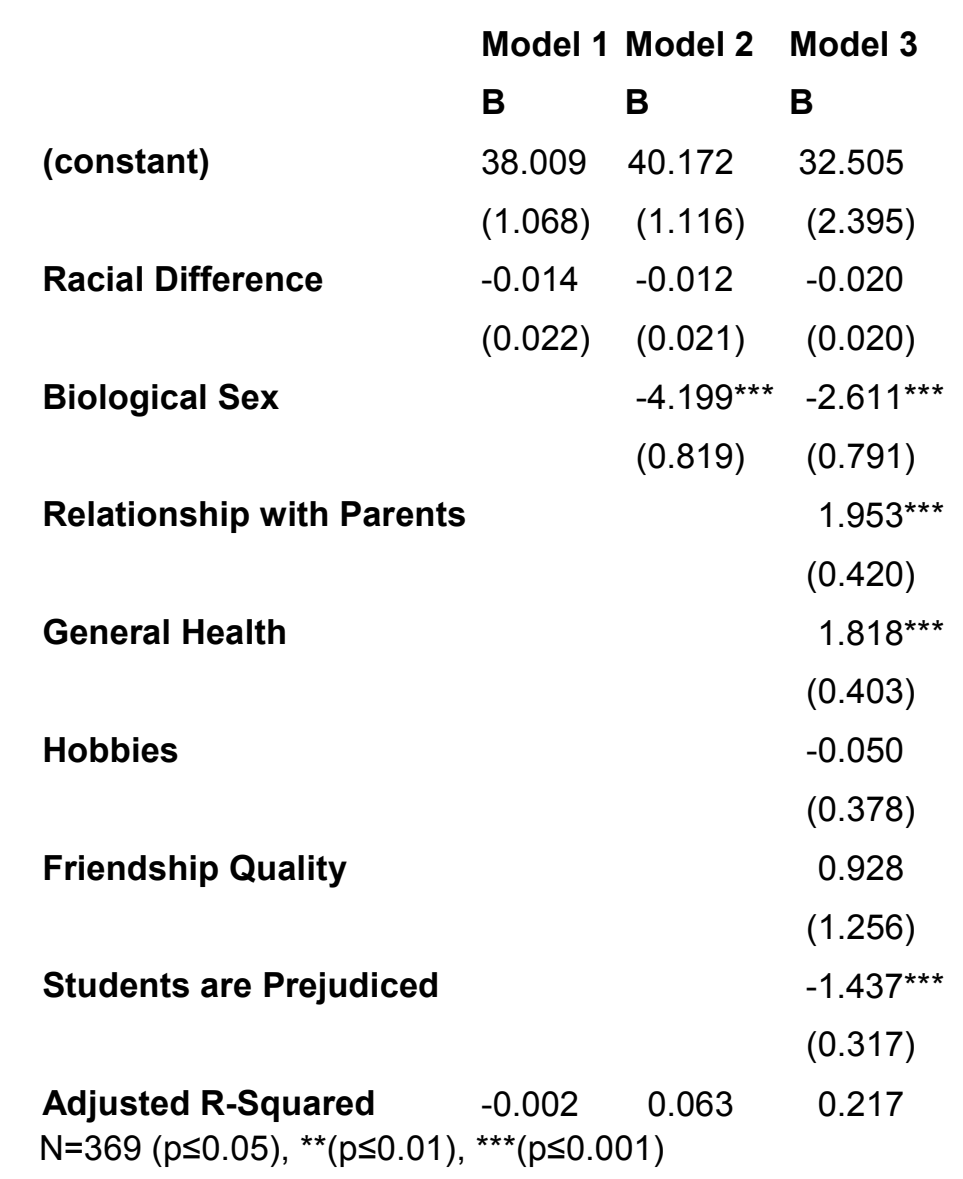


Table 20: Linear Unstandardized Coefficients from Linear Regression Models Predicting Hispanic Adolescent Self-Esteem

\begin{tabular}{llll} 
& \multicolumn{2}{l}{ Model 1 Model 2 } & Model 3 \\
& B & B & B \\
(constant) & 24.555 & 25.470 & 16.563 \\
& $(0.516)$ & $(0.544)$ & $(1.061)$ \\
Racial Difference & -0.005 & -0.005 & -0.005 \\
& $(0.011)$ & $(0.010)$ & $(0.009)$ \\
Biological Sex & & $-1.753^{* * *}$ & $-0.783^{*}$ \\
& & $(0.396)$ & $(0.351)$ \\
Relationship with Parents & & & $1.847^{* * *}$ \\
& & & $(0.179)$ \\
General Health & & & $1.037^{* * *}$ \\
Hobbies & & & $(0.179)$ \\
Friendship Quality & & & 0.013 \\
Students are Prejudiced & & & $(0.168)$ \\
& & 0.724 \\
Adjusted R-Squared & -0.002 & $(0.557)$ \\
N=368 ( $p \leq 0.05),{ }^{* *}(p \leq 0.01),{ }^{* * *}(p \leq 0.001)$ & -0.191 \\
\end{tabular}




\section{Table 21: T-Tests of Key Controls}

$\begin{array}{llcc}\begin{array}{l}\text { Demographic } \\ \text { Characteristics }\end{array} & \text { N } & \begin{array}{l}\text { T-Test of Perceived } \\ \text { Prejudice }\end{array} & \begin{array}{l}\text { T-Test on Relationship with } \\ \text { Parents }\end{array} \\ \text { White } & 4294 & 3.26 & 3.22^{* *} \\ \text { Black } & 1619 & 2.64 & 3.27^{*} \\ \text { Asian } & 270 & 2.91^{* * *} & 3.08 \\ \text { Other } & 649 & 3.10 & 3.14 \\ \text { Hispanic } & 743 & 3.01 & 3.15 \\ \text { Female } & 3356 & 3.12 & 3.14^{* * *} \\ \text { Male } & 3147 & 3.06 & 3.31^{* * *} \\ (\mathrm{p} \leq 0.05),{ }^{* *}(\mathrm{p} \leq 0.01),{ }^{* * *}(\mathrm{p} \leq 0.001) & & \end{array}$


Appendix B, Tables 22 and 23 code the racial difference variable such that beta coefficients represent the difference between adolescents with $0 \%$ racial difference scores and those with $100 \%$ racial difference scores.

\section{Table 22: Linear Unstandardized Coefficients from Linear Regression Models} Predicting Adolescent Mental Health

\section{Dependent Variable: CES-D}

\begin{tabular}{|c|c|c|c|c|}
\hline & $\begin{array}{l}\text { Model } 1 \\
\text { B }\end{array}$ & $\begin{array}{l}\text { Model } 2 \\
\text { B }\end{array}$ & $\begin{array}{l}\text { Model } 3 \\
\text { B }\end{array}$ & $\begin{array}{l}\text { Model } 4 \\
\text { B }\end{array}$ \\
\hline \multirow[t]{2}{*}{ (constant) } & 40.12 & 41.13 & 30.31 & 30.56 \\
\hline & $(0.18)$ & $(0.22)$ & $(0.67)$ & $(0.68)$ \\
\hline \multirow[t]{2}{*}{ Racial Difference } & $-2.36^{* * *}$ & -0.95 & $-1.08^{*}$ & $-2.11^{* * *}$ \\
\hline & $(0.51)$ & $(0.54)$ & $(0.49)$ & $(0.63)$ \\
\hline \multirow[t]{2}{*}{ Black } & & $-0.77^{* *}$ & $-1.43^{* * *}$ & $-1.88^{\star * *}$ \\
\hline & & $(0.26)$ & $(0.25)$ & $(0.39)$ \\
\hline \multirow[t]{2}{*}{ Asian } & & $-2.62^{* * *}$ & $-2.19^{* * *}$ & $-6.17^{* * *}$ \\
\hline & & $(0.57)$ & $(0.53)$ & $(1.15)$ \\
\hline \multirow[t]{2}{*}{ Other } & & $-1.55^{\star * *}$ & $-0.99^{*}$ & -1.67 \\
\hline & & $(0.48)$ & $(0.44)$ & $(0.86)$ \\
\hline \multirow[t]{2}{*}{ Hispanic Origin } & & $-1.52^{* * *}$ & $-1.37^{* *}$ & -1.22 \\
\hline & & $(0.48)$ & $(0.44)$ & $(0.99)$ \\
\hline \multirow[t]{2}{*}{ Biological Sex } & . & $-1.52^{* * *}$ & $-0.63^{* *}$ & $-0.59^{* *}$ \\
\hline & & $(0.22)$ & $(0.21)$ & $(0.21)$ \\
\hline \multirow[t]{2}{*}{ Relationship with Parents } & & & $2.21^{* * *}$ & $2.20^{* * *}$ \\
\hline & & & $(0.13)$ & $(0.13)$ \\
\hline \multirow[t]{2}{*}{ General Health } & & & $1.82^{* * *}$ & $1.82^{* * *}$ \\
\hline & & & $(0.12)$ & $(0.12)$ \\
\hline \multirow[t]{2}{*}{ Hobbies } & & & $0.44^{* * *}$ & $0.44^{* * *}$ \\
\hline & & & $(0.10)$ & $(0.10)$ \\
\hline \multirow[t]{2}{*}{ Friendship Quality } & & & 0.40 & 0.40 \\
\hline & & & $(0.35)$ & $(0.35)$ \\
\hline \multirow[t]{2}{*}{ Students are Prejudiced } & & & $-0.92^{\star * *}$ & $-0.93^{* * *}$ \\
\hline & & & $(0.09)$ & $(0.09)$ \\
\hline \multirow[t]{2}{*}{ Black*Racial Difference } & & & & 1.69 \\
\hline & & & & $(1.08)$ \\
\hline \multirow[t]{2}{*}{ Asian*Racial Difference } & & & & $10.17^{* * *}$ \\
\hline & & & & $(2.58)$ \\
\hline \multirow[t]{2}{*}{ Other*Racial Difference } & & & & 1.93 \\
\hline & & & & $(1.99)$ \\
\hline \multirow[t]{2}{*}{ Hispanic Origin*Racial Difference } & & & & -0.19 \\
\hline & & & & $(2.18)$ \\
\hline Adjusted R-Squared & 0.005 & 0.029 & 0.191 & 0.194 \\
\hline$=4110(p \leq 0.05),{ }^{* *}(p \leq 0.01),{ }^{* * *}(p \leq 0.00$ & & & & \\
\hline
\end{tabular}


Table 23: Linear Unstandardized Coefficients from Linear Regression Models Predicting Adolescent Self-Esteem

Dependent Variable: Modified Rosenburg Self-Esteem Scale

\begin{tabular}{|c|c|c|c|c|}
\hline & Model & & Model & \\
\hline & & Model 2 & & Model 4 \\
\hline & B & B & B & B \\
\hline (constant) & 24.95 & 25.33 & 16.89 & 16.86 \\
\hline & $(0.09)$ & $(0.10)$ & $(0.30)$ & $(0.30)$ \\
\hline Racial Difference & -0.40 & -0.24 & -0.28 & -0.24 \\
\hline & $(0.25)$ & $(0.26)$ & $(0.22)$ & $(0.28)$ \\
\hline Black & & $0.96^{* * *}$ & $0.84^{* * *}$ & $0.98^{* * *}$ \\
\hline & & $(0.12)$ & $(0.11)$ & $(0.17)$ \\
\hline Asian & & $-1.25^{* * *}$ & $-0.79^{* * *}$ & $-2.25^{* * *}$ \\
\hline & & $(0.27)$ & $(0.24)$ & $(0.51)$ \\
\hline Other & & -0.31 & 0.01 & -0.03 \\
\hline & & $(0.23)$ & $(0.20)$ & $(0.39)$ \\
\hline Hispanic Origin & & -0.19 & 0.02 & 0.28 \\
\hline & & $(0.23)$ & $(0.20)$ & $(0.45)$ \\
\hline Biological Sex & . & $-1.11^{* * *}$ & $-0.65^{* * *}$ & $-0.64^{* * *}$ \\
\hline & & $(0.11)$ & $(0.10)$ & $(0.10)$ \\
\hline Relationship with Parents & & & $1.64^{* * *}$ & $1.64^{* * *}$ \\
\hline & & & $(0.06)$ & $(0.06)$ \\
\hline General Health & & & $0.98^{* * *}$ & $0.98^{* * *}$ \\
\hline & & & $(0.05)$ & $(0.05)$ \\
\hline Hobbies & & & $0.11^{* *}$ & $0.11^{* *}$ \\
\hline & & & $(0.04)$ & $(0.04)$ \\
\hline Friendship Quality & & & $0.67^{* \star *}$ & $0.68^{* * *}$ \\
\hline & & & $(0.16)$ & $(0.16)$ \\
\hline Students are Prejudiced & & & $-0.15^{\star *}$ & $-0.15^{* * *}$ \\
\hline & & & $(0.04)$ & $(0.04)$ \\
\hline Black*Racial Difference & & & & -0.48 \\
\hline & & & & $(0.48)$ \\
\hline Asian*Racial Difference & & & & $3.61^{* *}$ \\
\hline & & & & $(1.15)$ \\
\hline Other*Racial Difference & & & & 0.13 \\
\hline & & & & $(0.90)$ \\
\hline Hispanic Origin*Racial Difference & & & & -0.62 \\
\hline & & & & $(0.98)$ \\
\hline $\begin{array}{l}\text { R-Squared } \\
N=4114(p \leq 0.05),{ }^{* *}(p \leq 0.01),{ }^{* * *}(p \leq 0.001)\end{array}$ & 0.001 & 0.048 & 0.292 & 0.294 \\
\hline
\end{tabular}


Appendix B, Figure 5: Thomas F. Pettigrew's Reformulated Contact Theory Model (1988)

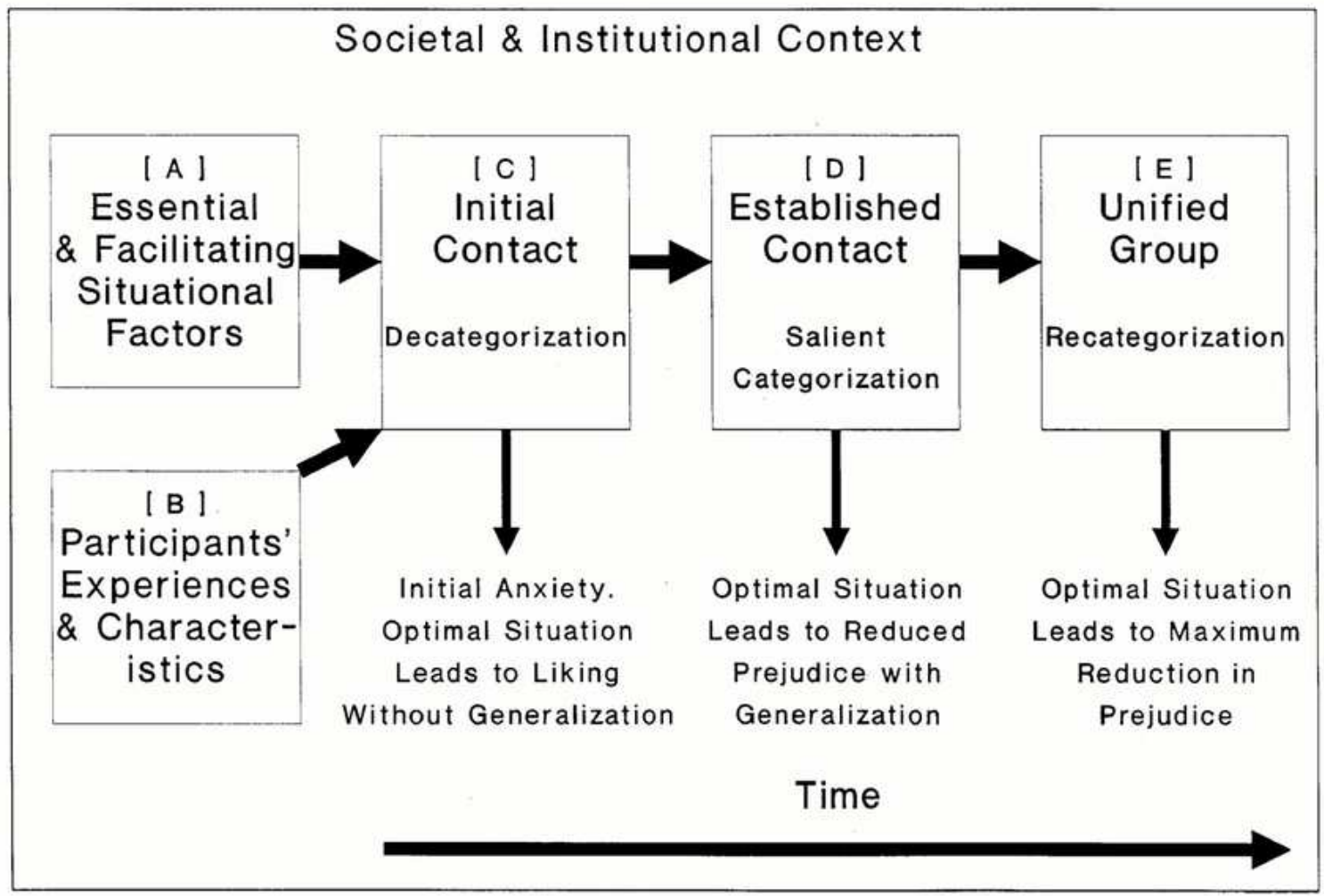

